\title{
Numerical modelling of the migration direction of tidal sand waves over sand banks
}

\author{
S. Leenders ${ }^{a, b, c}$, J.H. Damveld ${ }^{d}$, J. Schouten ${ }^{b}$, R. Hoekstra ${ }^{b}$, T.J. Roetert ${ }^{b}$, B.W. Borsje ${ }^{\text {d,* }}$ \\ ${ }^{a}$ Hydraulic Engineering, Delft University of Technology, Delft, the Netherlands \\ ${ }^{\mathrm{b}}$ Hydraulic Engineering, Deltares, Delft, the Netherlands \\ ${ }^{\mathrm{c}}$ Royal Boskalis Westminster N.V, Papendrecht, the Netherlands \\ ${ }^{\mathrm{d}}$ Water Engineering and Management, University of Twente, Enschede, the Netherlands
}

\section{A R T I C L E I N F O}

\section{Keywords:}

Morphodynamic modelling

Tidal sand waves

Migration direction

Sand banks

Delft3D

North sea

Offshore wind farm

\begin{abstract}
A B S T R A C T
Tidal sand waves are large-scale bed forms found in shallow sandy seas, which show a migration of several meters per year. Field data from the Dutch part of the North Sea revealed a migration pattern causing bidirectional migration of sand waves over a sand bank, resulting in sand wave migration uphill from both sides of the sand bank. In order to understand the physical mechanisms behind this migration behaviour, we study the inclusion of a sand bank under a sand wave field using the numerical model Delft3D. First, the schematized model set-up (i.e. schematized bathymetry and simple tidal forcing) showed that the alteration of the tidal flow by a sand bank resulted in tide-averaged horizontal flow towards the top of the sand bank, causing the bidirectional migration of sand waves over the sand bank. Second, a case study was performed in which a more complex model set-up was used (bathymetry and tidal forcing identical to a study site in the North Sea where an offshore wind farm is developed). Here, the model results revealed migration directions comparable to field observations. The results open opportunities to explore modelling migration patterns of sand wave fields for offshore wind farm development in areas with complex bathymetric environments.
\end{abstract}

\section{Introduction}

The offshore wind industry set a target of $460 \mathrm{GW}$ installed capacity for offshore wind in the EU by 2050 (Jeffrey and Sedgwick, 2011). Taking into account the target of 2020 (EU-OEA, 2012), being $40 \mathrm{GW}$, the growth of the offshore wind industry will be significant in the coming decades. The North Sea and Baltic Sea account for almost half of the potential for offshore wind energy in the EU. This will result in more human interaction with the dynamic sandy seabed in the North Sea, e.g. foundations of structures, seabed protections and submarine cables. In shallow seas with sandy beds characterized by tidal motion, such as the North Sea, rhythmic large-scale bed forms are present. Tidal sand waves, with wavelengths in the order of hundreds of meters (Besio et al., 2008), heights up to $20 \%$ of the water depth (Knaapen et al., 2001) and migration speeds up to tens of meters per years (Blondeaux and Vittori, 2016), are the most dynamic large-scale bed form. Given the migration, sand waves can pose a threat for the offshore wind industry. For instance, exposure of submarine cables, interaction with wind turbine foundations and destabilization of bed protections (Németh et al.,
2003). A thorough understanding of sand wave dynamics and subsequent improvement of its prediction is expected to result in smart design of submarine cable layouts and scour protections, thereby lowering the risk for the offshore wind sector and consequently bring down the levelized cost of electricity from offshore wind (Roetert et al., 2017).

Hulscher (1996) explained that the formation of sand waves is governed by the tidal motion in combination with the wavy seabed. Tide-averaged vertical recirculating cells are the result of the interaction of an oscillatory tidal current interacting with a wavy seabed. Near the seabed a balance between the residual current generated sediment transport from the trough to the crest and the gravity generated sediment transport from the crest to the trough controls the development of the sand wave.

Sand wave models are developed to gain understanding in the physical mechanisms behind sand wave dynamics and are relevant when limited or no bathymetric survey data is available. A distinction is made between linear and non-linear models. Linear stability models examine properties and processes relevant for the initial stage of small-amplitude sand wave formation. The model approach by Hulscher (1996) was the

\footnotetext{
* Corresponding author.

E-mail address: b.w.borsje@utwente.nl (B.W. Borsje).
} 
first to describe this, using the three dimensional shallow water equations. This model was extended by Gerkema (2000); Komarova and Hulscher (2000) and Besio et al. (2003a). Németh et al. (2002); Besio et al. (2003b) and Besio et al. (2004) investigated sand wave migration, introducing tidal asymmetry, upstream migration and a residual current respectively. A depth dependent eddy viscosity with a no-slip condition at the bed was introduced by Blondeaux and Vittori (2005a, b) and Besio et al. (2006). In which both bed and suspended load transport was included. Additional linear stability analysis considered grain sorting (Van Oyen and Blondeaux, 2009a, b), influence of biota (Borsje et al., 2009; Damveld et al., 2019), non-erodible layers (Blondeaux et al., 2016) and storms (Campmans et al., 2017). All linear models are based on linear stability analysis, in which the growth rate of different small perturbations is determined. The perturbation with the largest positive growth rate will prevail in the system due to weak non-linearity (Dodd et al., 2003), termed the fastest growing mode.

Including non-linear effects made it possible to model sand waves from the initial stage to a stable equilibrium (Németh et al., 2006, 2007; Van den Berg et al., 2012), with the restriction of a domain equal to the fastest growing mode. In this way the formation of very long sand waves over the entire domain is supressed.

Recently a complex numerical model (Delft3D) is used to investigate sand wave dynamics, which has the advantage to include many processes in a sophisticated way. Using the k- $\varepsilon$ turbulence formulation, the formation stage of sand waves was successfully modelled by Borsje et al. (2013). The inclusion of suspended sediment load transport supressed very long sand waves, allowing for a domain larger than the fastest growing mode (Borsje et al., 2014). Furthermore, Van Gerwen et al. (2018) showed that the inclusion of suspended sediment load transport and tidal asymmetry both had a dampening effect on the equilibrium height of sand waves and found equilibrium heights in the same range as field observations.

Besides modelling studies, data driven analyses give insight in sand wave dimensions and dynamics. A location for which a sand wave field is investigated is Borssele Wind Farm Zone in the Dutch part of the North Sea (Fig. 1a). Within the sand wave field (Fig. 1b) bidirectional migration of sand waves is observed (Fig. 1c) (Deltares, 2016a). Based on historical bathymetric surveys of Borssele Wind Farm Zone from the year 2010 and 2015, the migration direction and migration speed are derived using the gradient method and cross-correlation technique respectively (Deltares, 2016a, b). In this techniques, first megaripples and sand banks are filtered out to solely look at sand wave dynamics. A mild sloping stoss side and a steeper lee side in the direction of migration are characteristic for migrating sand waves. Sand waves also tend to migrate in the direction perpendicular to the orientation of the sand wave crest. The migration direction can therefore be approximated by the direction of the steepest gradient of the 2015 bathymetric survey, known as the gradient method. The obtained direction is used to draw a number of transects with a length of $800 \mathrm{~m}$ along which the cross correlation technique is used to find the migration speed. The length of the transects is chosen such that each transect fully covers at least one sand wave. For these transects, sand wave elevations are derived from both the 2010 and 2015 bathymetric surveys. By artificially shifting a transect derived from the first bathymetric data set towards a transect derived from the second bathymetric data set the offset between the two data sets can be determined. The offset for which the correlation between both transects is highest is considered as the sand wave migration distance over the period considered (Deltares, 2016b).

The observed behaviour of bidirectional migration of sand waves is hypothesised to be related to the underlying sand banks, which have a wavelength in the order of $5-10 \mathrm{~km}$, an elevation up to half of the local water depth (Hulscher, 1996) and with reference to the principal tidal current, their orientation is rotated $10-30^{\circ}$ anticlockwise (in the Northern Hemisphere) (Hulscher, 1996). Data driven analyses are currently used to predict sand wave field dynamics in consultancy practice. However, data studies give insight in sand wave dynamics without revealing the physical mechanisms responsible for the observations.

So far, modelling the migration direction of sand waves in the North Sea is only examined using a flat underlying seabed (Németh et al., 2002; Besio et al., 2004; Borsje et al., 2013). Recently, bidirectional migration of sand waves was observed and modelled in the South China Sea (Jiang and Lin, 2016). In their model, they focussed only on the migration direction of sand waves at specific locations on both sides of a tidal ridge, by assuming that the sand wave shape is unchanged during migration and they only incorporated bed load sediment transport in the model. In this paper, we go one step further since we want to retrieve a mechanistic understanding of sand wave migration over the full sand bank, based on the morphological evolution by taking into account both bed load and suspended load transport. Therefore, a schematized model configuration (i.e. schematized bathymetry and simple tidal forcing) of the numerical shallow water model Delft3D is applied, followed by a case study in the North Sea (i.e. bathymetry and tidal forcing as observed in the study site). Hereto, the transect model presented by Van Gerwen et al. (2018) is extended in a second horizontal dimension to be able to include both slopes of the sand bank. With this 3D model the migration direction is investigated in a schematized representation of reality. Therefore this model is referred to as the Schematized Delft3D model (further referred to as Schematized model). Subsequently, a model developed by Deltares (2015) for Borssele Wind Farm Zone, is modified by adding vertical resolution and increasing the horizontal resolution to make sand wave modelling possible. This model is used to investigate whether bidirectional migration observed in the field is reproduced. This Delft3D model is referred to as the North Sea model.
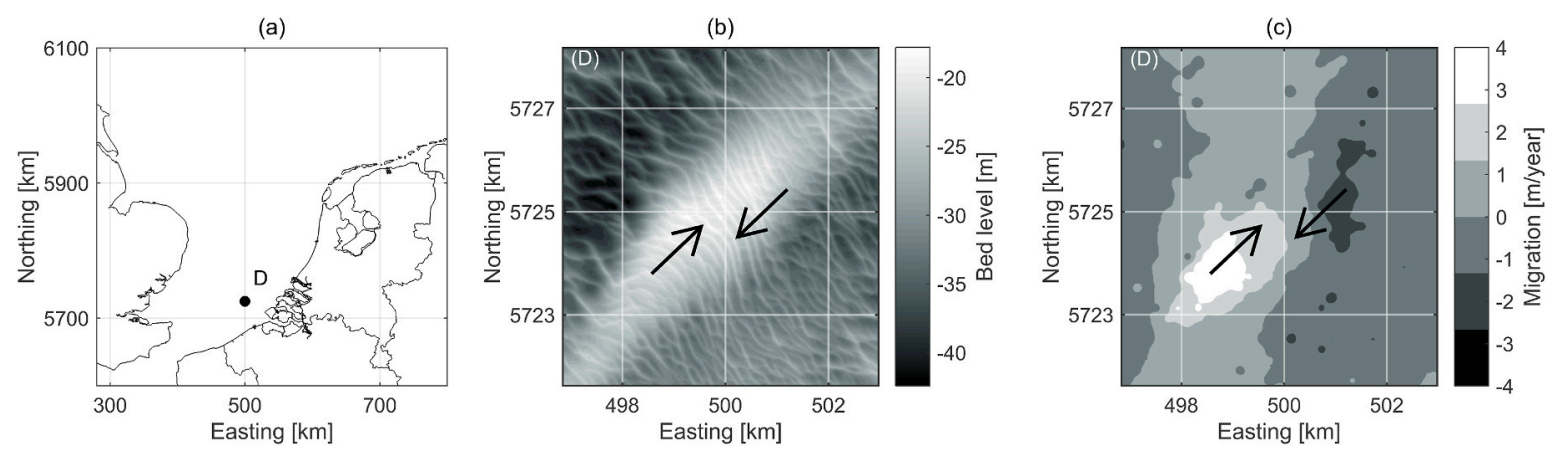

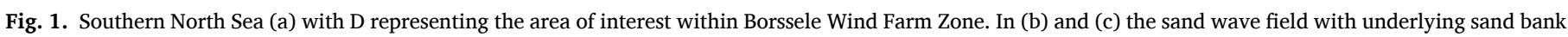

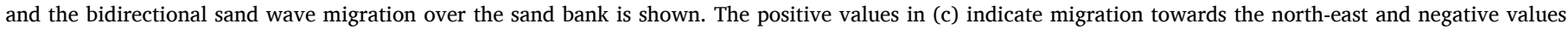
indicate migration towards the south-west. This is graphically displayed by the arrows in both figure (b) and (c). 
The aim of this paper is twofold. First, the Schematized model is used to unravel the hydrodynamic and morphodynamic processes regarding the migration direction of sand waves over a sand bank. Second, in the case study we aim to attain modelling sand wave dynamics in a realistic representation of a sand wave field in Borssele Wind Farm Zone using the North Sea model.

The outline of this paper is as follows. First, Section 2 presents the model description and set-up of the Schematized model, followed by its results in Section 3. The case study, including a brief description of the North Sea model is given in Section 4. Finally, the approach in this paper is discussed in Section 5, followed by the main conclusion in Section 6 .

\section{Model description: Schematized Delft3D model}

The migration direction of sand waves over a sand bank is modelled using the numerical shallow water model Delft3D (Lesser et al., 2004). In this section, first the overall model formulations for the hydrodynamics, sediment transport and bed evolution are presented. Second, the model set-up of the Schematized model (based on Van Gerwen et al. (2018)) are presented. For the sake of brevity, we limit ourselves to the main details regarding the model equations. The interested reader is referred to the above references and the Delft3D manual (Deltares, 2012), for a more extensive description of the model formulations.

\subsection{Geometry}

We define a Cartesian coordinate system (Fig. 2a) with horizontal coordinates $x$ and $y$, vertical coordinate $z$, and corresponding velocity components $u, v$ and $w$, respectively. The free surface level is denoted by $z=\zeta$, with $z=0$ as the undisturbed water level. The bed is located at $z=z_{b}, H_{0}$ denotes the reference water depth (without bed perturbations) and $h$ is the local water depth.
A trapezium-shaped sand bank with height $H_{\text {bank }}$, width $B_{\text {bank }}$, longitudinal length $L_{b a n k}$ (representing an infinite extent (Roos and Hulscher, 2003)) and slope $I_{\text {bank }}$ is mimicked on top of a flat bed (Fig. 2b and $c)$. The angle $\left(\Theta_{\text {bank }}\right)$ between the direction of the principal tidal component (x-direction) and the sand bank is typically $30^{\circ}$ anticlockwise in the North Sea (Northern Hemisphere) (Hulscher, 1996). The sand waves superimposed on the tidal sand bank have a perpendicular orientation to the principal tidal component (Besio et al., 2008).

\subsection{Governing equations}

The hydrodynamics are described by the three-dimensional shallow water equations, a continuity equation, supplemented with appropriate boundary conditions. Turbulence is represented by a spatiotemporally varying vertical eddy viscosity. The hydrodynamic model equations are solved by applying a sigma coordinate transformation in the vertical, and read

$$
\begin{aligned}
& \frac{\partial u}{\partial t}+u \frac{\partial u}{\partial x}+v \frac{\partial u}{\partial y}+\frac{\omega}{h} \frac{\partial u}{\partial \sigma}-f v=-\frac{1}{\rho_{w}} P_{u, x}+F_{u, x}+\frac{1}{h^{2}} \frac{\partial}{\partial \sigma}\left(\nu_{t} \frac{\partial u}{\partial \sigma}\right), \\
& \frac{\partial v}{\partial t}+u \frac{\partial v}{\partial x}+v \frac{\partial v}{\partial y}+\frac{\omega}{h} \frac{\partial u}{\partial \sigma}+f u=-\frac{1}{\rho_{w}} P_{u, y}+F_{u, y}+\frac{1}{h^{2}} \frac{\partial}{\partial \sigma}\left(\nu_{t} \frac{\partial u}{\partial \sigma}\right), \\
& \frac{\partial \omega}{\partial \sigma}=-\frac{\partial \zeta}{\partial t}-\frac{\partial(h u)}{\partial x}-\frac{\partial(h v)}{\partial y},
\end{aligned}
$$

in which $\omega$ is the vertical velocity in the moving $\sigma$-plane, $f$ the Coriolis coefficient, $\rho_{w}$ the water density, $P_{u, x}$ and $P_{u, y}$ the hydrostatic pressure gradients, $F_{u, x}$ and $F_{u, y}$ the horizontal Reynold's stresses and $\zeta$ the free surface elevation. The vertical eddy viscosity $\nu_{t}$ is calculated using the $k-\varepsilon$ turbulence model (e.g. Burchard et al. (2008)). (a)

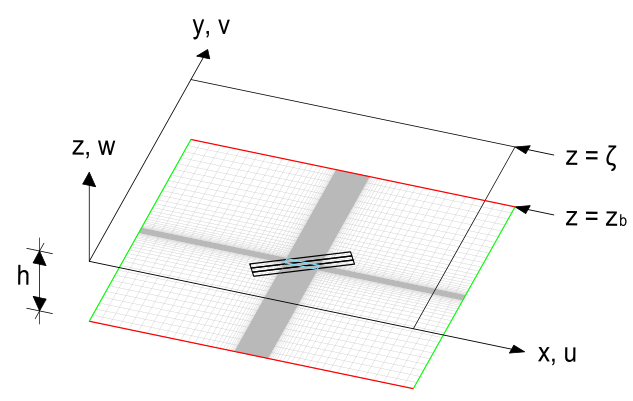

(b)

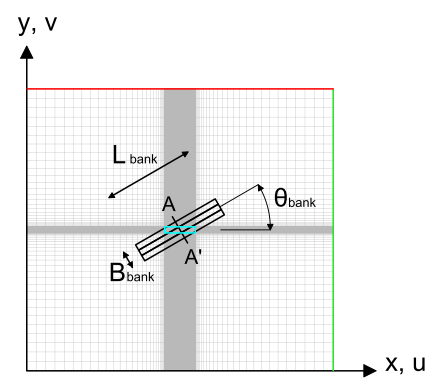

(c)

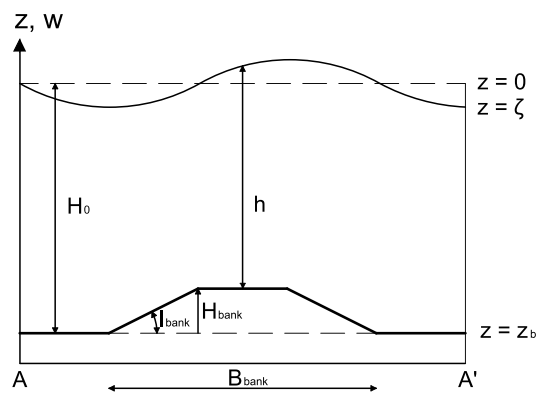

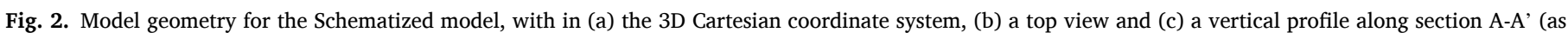

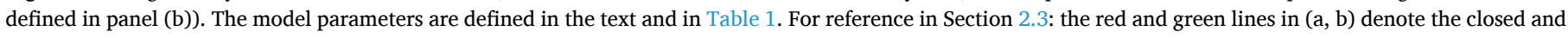
open boundaries, respectively. The grey lines in $(\mathrm{a}, \mathrm{b})$ denote the grid with the blue box indicating the area of interest. 
The boundary conditions at the bed $(\sigma=-1)$ and at the free surface $(\sigma=0)$ read

$\frac{1}{\rho_{w}} \tau_{b, x}=\frac{\nu_{t}}{h} \frac{\partial u}{\partial \sigma}=\frac{g u_{b, x}\left|u_{b}\right|}{C^{2}}, \frac{1}{\rho_{w}} \tau_{b, y}=\frac{\nu_{t}}{h} \frac{\partial v}{\partial \sigma}=\frac{g u_{b, y}\left|u_{b}\right|}{C^{2}}, \omega=0$,

$\frac{\nu_{t}}{h} \frac{\partial u}{\partial \sigma}=\frac{\nu_{t}}{h} \frac{\partial \nu}{\partial \sigma}=0, \omega=0$,

respectively. Here $\tau_{b, x}$ and $\tau_{b, y}$ are the bed shear stresses in the associated horizontal directions, $g$ the gravitational acceleration, $u_{b, x}$ and $u_{b, y}$ the horizontal velocities in the first layer above the bed in $x$ - and $y$-direction, respectively, and $C$ the Chézy coefficient.

Sediment transport is included as both bed load and suspended load. Following Lesser et al. (2004), the magnitude of the bed load sediment transport vector $\left|\vec{S}_{b}\right|$ is calculated according to

$\left|\vec{S}_{b}\right|=0.5 \rho_{s} D_{50} u * D_{*}^{-0.3} T$,

where $\rho_{s}$ is the sediment density, $D_{50}$ the median grain size and $u_{*}$ the effective shear velocity. $D *$ and $T$ are the dimensionless particle diameter and dimensionless bed shear stress, respectively, and read

$D_{*}=D_{50}\left[\frac{\left(\rho_{s} / \rho_{w}-1\right) g}{\nu^{2}}\right]^{\frac{1}{3}}, T=\frac{\tau_{b}^{\prime}-\tau_{c r}}{\tau_{c r}}$, with $\nu$ as the kinematic viscosity of water, $\tau_{b}^{\prime}$ the grain-related bed shear stress and $\tau_{c r}$ the critical bed shear stress based on the classical Shields curve. Furthermore, bed load transport is affected by bed level gradients, which causes sediment to move more difficult upslope than downslope. These slope effects are included in the model in both longitudinal and transverse directions (Lesser et al., 2004). Longitudinal slope effects are accounted for by introducing a correction factor to the magnitude of the bed load transport which depends on a user-defined tuning parameter $\left(\alpha_{b s}\right)$, set to 3 following Van Gerwen et al. (2018). Also, a transverse bed slope correction is applied, which modifies the direction of the bed load transport vector. The related tuning parameter $\left(\alpha_{b n}\right)$ is set to its default value of 1.5 .

The transport of suspended sediment in the water column is calculated by solving a three-dimensional advection-diffusion equation

$$
\frac{\partial c}{\partial t}+\frac{\partial(c u)}{\partial x}+\frac{\partial(c v)}{\partial y}+\frac{\partial\left(c\left[w-w_{s}\right]\right)}{\partial z}=\frac{\partial}{\partial x}\left(\varepsilon_{\mathrm{s}, \mathrm{x}} \frac{\partial c}{\partial x}\right)+\frac{\partial}{\partial y}\left(\varepsilon_{\mathrm{s}, y} \frac{\partial c}{\partial y}\right)+\frac{\partial}{\partial z}\left(\varepsilon_{\mathrm{s}, z} \frac{\partial c}{\partial z}\right),
$$

in which $c$ is the sediment concentration and $w_{s}$ the sediment settling velocity. Furthermore, $\varepsilon_{s, \mathrm{x}}, \varepsilon_{s, \mathrm{y}}$ and $\varepsilon_{\mathrm{s}, \mathrm{z}}$ are the sediment diffusivity coefficients in $x, y$ and $z$ direction, respectively. To distinguish bed load from suspended load, a reference height $(a=0.01 h)$ is defined, which marks the transition between the two modes of transport (see Van Rijn, 2007). For a more comprehensive elaboration on the initial and boundary conditions, and other details on the model formulations we
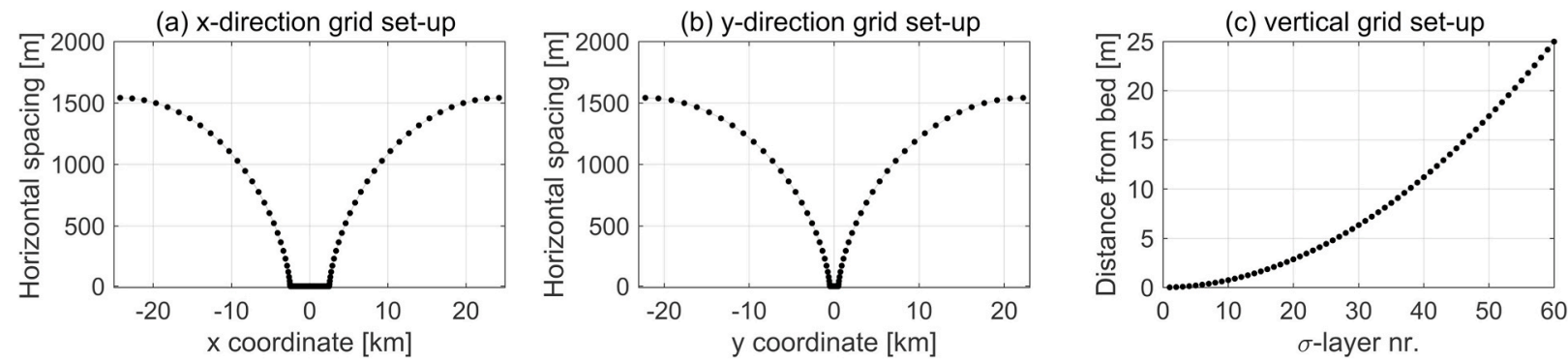

(d) Schematized sand bank (without sand waves superimposed)

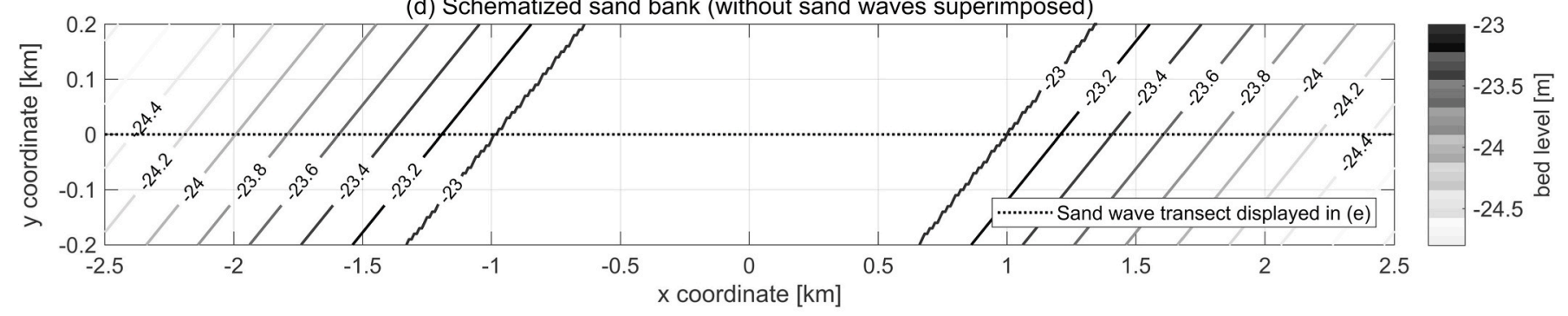

(e) Transect along y-coordinate

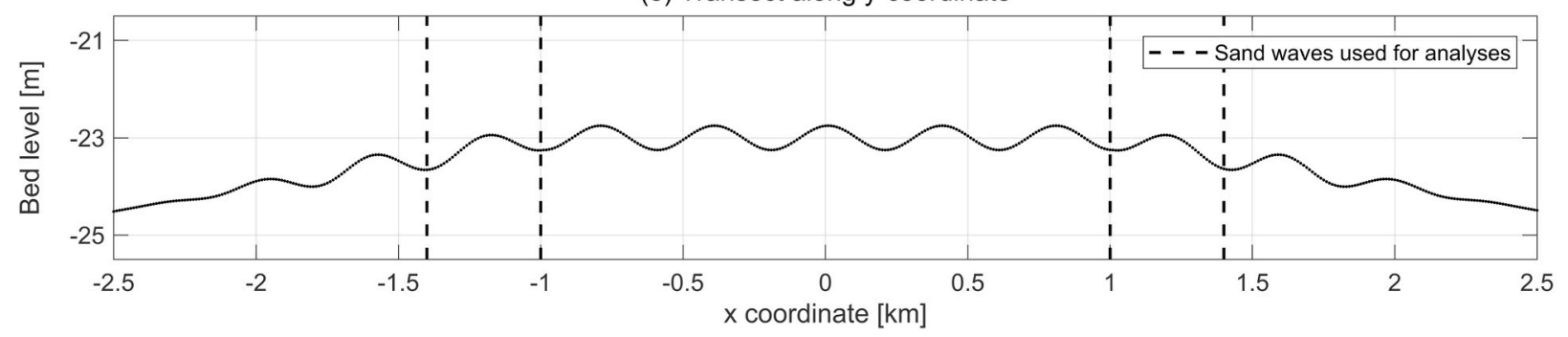

Fig. 3. The horizontal grid distribution in (a) $x$-direction, and (b) $y$-direction. The distribution of the $\sigma$-layers over the water column (c). The schematized sand bank (without sand waves superimposed) (d), with indicated the transect displayed in panel (e). In (e) this transect is shown with sand waves superimposed over the sand bank. The vertical black dotted lines indicate the locations of the sand waves used for the analyses further on. 
refer the reader to Lesser et al. (2004) and the Delft3D user manual (Deltares, 2012). Finally, the bed evolution is governed by the sediment continuity (Exner) equation.

\subsection{Model set-up and parameter choices}

The horizontal model dimension is $50 \mathrm{~km}$ in the $x$-direction and 46 $\mathrm{km}$ in the $y$-direction. In both directions the horizontal grid resolution is variable (Fig. 2). The area of interest comprises $5 \mathrm{~km}$ in the $x$-direction and $1 \mathrm{~km}$ in the $y$-direction. In this central part of the domain the grid resolution is 10 by $10 \mathrm{~m}$. Outside the area of interest the grid size increases gradually in both horizontal directions to $1500 \mathrm{~m}$ at the boundaries (Fig. 3a and Fig. 3b). As shown by Borsje et al. (2013, 2014) and Van Gerwen et al. (2018), the grid extensions in horizontal direction are sufficient to minimize influences of the lateral boundaries on the area of interest. In the vertical dimension the model contains $60 \sigma$-layers with a resolution of $0.05 \%$ of the local water depth near the bed, gradually decreasing towards the free surface boundary (Fig. 3c).

The sand bank is situated on a flat bed at a reference water depth of $25 \mathrm{~m}$ in the central fine-spaced part of the domain (Figs. 2 and 3d). It has a width of $3 \mathrm{~km}$, a length of $15 \mathrm{~km}$, a variable height of 2 and $10 \mathrm{~m}$, and a variable slope of $1 / 500$ and $1 / 100$. The sinusoidal sand waves superimposed over the sand bank have an amplitude of $0.25 \mathrm{~m}$ and a wavelength of $400 \mathrm{~m}$ (Fig. 3e), which is the representative wavelength for a North Sea situation for the given grain size, water depth and flow velocity amplitude (Borsje et al., 2014). A sinusoidal envelope function (quarter sine) is applied which ensures a gradual increase of the sand wave amplitude from the flat bed towards the sand wave field over a length of $1 \mathrm{~km}$ (starting at the edge of the fine-spaced grid) (Fig. 3e).

At the lateral boundaries (normal to the $x$-axis, green lines in Fig. 2) weakly-reflective Riemann boundaries are applied (Verboom and Slob, 1984). This type of boundaries allows outgoing waves to cross the lateral boundary without reflecting back into the domain. At these boundaries, the model is forced with a semi-diurnal $\mathrm{S}_{2}$ tidal signal, with a tidal velocity amplitude of $U_{\mathrm{S} 2}=0.65 \mathrm{~m} / \mathrm{s}$ and a tidal period of $12 \mathrm{~h}$ (see Borsje et al. (2013)). This symmetrical tidal forcing can be superimposed by other tidal components, like $U_{\mathrm{S} 0}$ or $U_{\mathrm{S} 4}$ (see Table 1 ). The remaining lateral boundaries (parallel to the $x$-axis, red lines in Fig. 2) are closed, $i$. e. zero velocities normal to the boundary. Following Borsje et al. (2013, 2014), the model is run for two tidal cycles, where the first tidal cycle is used for spin-up and the second to simulate morphological development. The hydrodynamic time step is set to $12 \mathrm{~s}$. Following Van Gerwen et al. (2018), the roughness of the bed is expressed in a Chézy roughness value of $75 \mathrm{~m}^{1 / 2} / \mathrm{s}$ and the median grain size is $350 \mu \mathrm{m}$. These physical parameters settings represent typical North Sea conditions where sand waves are observed (Borsje et al., 2009).

The model results are analysed on migration direction and migration rate for the sand waves on the left and right flank along the transect, indicated by the dashed lines (Fig. 3e). The left flank is the part of the transect with sloping underlying bathymetry and negative $x$-coordinates from approximately $-2.5 \mathrm{~km}$ to $-1 \mathrm{~km}$. The right flank is the part of the transect with sloping underlying bathymetry and positive $x$-coordinates, from approximately $1 \mathrm{~km}-2.5 \mathrm{~km}$. Migration in the positive $x$-direction is defined as positive migration. The migration rate is determined by analysing the horizontal displacement of the initial sand wave crest position after one tidal cycle, following Borsje et al. (2013).

\section{Results schematized model}

The Schematized model was run for six different combinations of settings (Case I-VI), as presented in Table 1. Below we first present a summary of the migration rates for all six Cases, and subsequently we analyse these results by means of tide-averaged flow patterns and sediment transport.

\subsection{Migration rates}

Sand waves over a flat underlying seabed show no migration for a symmetrical forcing (not shown here). To investigate the influence of the sand bank on sand wave migration, the tidal forcing is therefore taken symmetrical for the first four cases. For Case I, the migration direction for the sand waves is towards the top of the sand bank. The migration rate is $0.53 \mathrm{~m}$ /year, looking at the sand wave on the left flank. For the sand wave on the right flank a migration rate of $-0.33 \mathrm{~m}$ /year is observed.

Case II considers a smaller sediment grain size compared to Case I, which results in higher suspended load sediment transport. The resulting migration rates are higher but in the same order (less than a meter per year). The sand wave on the left flank, experiences a migration rate of $0.62 \mathrm{~m} /$ year, whereas the migration rate for the sand wave on the right flank is $-0.34 \mathrm{~m} /$ year.

Next, in Case III the sand bank height is increased and all other settings are equal to Case I. Again, migration of the sand waves on both flanks is towards the top of the sand bank. However, in this case the migration rates are an order higher compared to the migration rates observed for the lower sand banks of Case I and Case II. The migration rate on the left flank is $7.61 \mathrm{~m}$ /year and on the right flank $-4.49 \mathrm{~m}$ /year.

In Case IV the sediment grain size is decreased similar to Case II, and the height of the sand bank similar as in Case III. Compared to Case III, the migration rate increases, but stays in the same order (several meters per year). The migration rate for the sand wave on the left flank is 9.47 $\mathrm{m}$ /year and for the right flank $-5.35 \mathrm{~m} /$ year.

For cases with asymmetrical tidal conditions (Case V and Case VI), the sand bank and sediment properties are identical to the settings of

Table 1

Overview of the values and dimensions of the model parameters used for the different cases.

\begin{tabular}{|c|c|c|c|c|c|c|c|c|}
\hline Description & Symbol & Values & & & & & & Dims. \\
\hline Reference water depth & $H_{0}$ & 25 & & & & & & $\mathrm{~m}$ \\
\hline Tidal sand bank orientation & $\theta_{\text {bank }}$ & 30 & & & & & & degrees \\
\hline Tidal sand bank width & $B_{\text {bank }}$ & 3 & & & & & & $\mathrm{~km}$ \\
\hline Sand wave amplitude & $A_{0}$ & 0.5 & & & & & & $\mathrm{~m}$ \\
\hline Sand wave length & $L_{0}$ & 400 & & & & & & $\mathrm{~m}$ \\
\hline Case & & I & II & III & IV & $\mathrm{V}$ & VI & \\
\hline Amplitude of horizontal $S_{2}$ tidal velocity & $U_{S 2}$ & 0.65 & 0.65 & 0.65 & 0.65 & 0.65 & 0.65 & $\mathrm{~m} \mathrm{~s}^{-1}$ \\
\hline Tidal sand bank height & $H_{\text {bank }}$ & 2 & 2 & 10 & 10 & 10 & 10 & $\mathrm{~m}$ \\
\hline Tidal sand bank slope & $I_{\text {bank }}$ & $1 / 500$ & $1 / 500$ & $1 / 100$ & $1 / 100$ & $1 / 100$ & $1 / 100$ & - \\
\hline Median grain size & $D_{50}$ & 350 & 200 & 350 & 200 & 200 & 200 & $\mu \mathrm{m}$ \\
\hline Magnitude of horizontal $S_{0}$ tidal velocity & $U_{S 0}$ & & & & & 0.05 & & $\mathrm{~m} \mathrm{~s}^{-1}$ \\
\hline Amplitude of horizontal $S_{4}$ tidal velocity & $U_{S 4}$ & & & & & & 0.05 & $\mathrm{~m} \mathrm{~s}^{-1}$ \\
\hline
\end{tabular}


Case IV (Table 1). In Case V, we observe migration on the left flank of the sand bank in the direction of the residual current. The migration rate observed for the sand wave on the left flank is $18.95 \mathrm{~m} /$ year. On the right flank the sand wave migration in the negative direction is reduced to almost zero, showing a migration of $-0.01 \mathrm{~m} /$ year.

Case VI includes a higher order tidal constituent in the tidal signal. Similar to the cases with symmetrical tidal conditions, sand wave migration towards the top of the sand bank is observed. The migration magnitude on the left flank is significantly lower compared to Case V, whereas the migration rate on the right flank is higher compared to Case $\mathrm{V}$, being $5.68 \mathrm{~m} /$ year and $-7.90 \mathrm{~m} /$ year respectively.

\subsection{Physical explanation}

For symmetrical tidal forcing sand waves show no net migration over a flat underlying bed. This can be explained by the symmetrical vertical tide-averaged recirculating cells over a sand wave (Hulscher, 1996). In the cases with symmetrical tidal forcing and the inclusion of a sand bank, sand wave migration is however observed and can be explained by the alteration of the hydrodynamics due to the interaction of the sand bank and the tidal flow. During flood flow the flow accelerates due to continuity towards the top of the sand bank and the maximum velocity is achieved upstream of the sand bank top (Fig. 4b) (Roos and Hulscher, 2003). In addition, Roos and Hulscher (2003) show that the flow experiences a deflection relative to the direction of the flow, enlarged by the Coriolis effect (towards the right in the Northern Hemisphere) (Fig. 4b). During ebb flow the same processes are observed in opposite direction (Fig. 4c). Averaged over a tidal cycle the sand bank generates a horizontal residual flow as displayed in Fig. 4d.

As soon as sand waves are included in the schematized model and the flow is symmetrical (Case I-IV), the hydrodynamic results (Appendix; Figs 11 and 12) are qualitatively the same as described for the sand bank without sand waves (Fig. 4); the horizontal tide-averaged residual flow parallel to the sand bank has a component on both flanks towards the top of the sand bank. This component results in a distortion of the vertical tide-averaged recirculating cells of the sand waves and tide-averaged residual flow over the entire water column towards the top is observed. For Case 1, the resulting sediment transport rates are displayed in Fig. 5a. Both the tide-averaged bed load and suspended load sediment transport rates show a negative gradient around the sand wave

(a) Initial bed level [m]

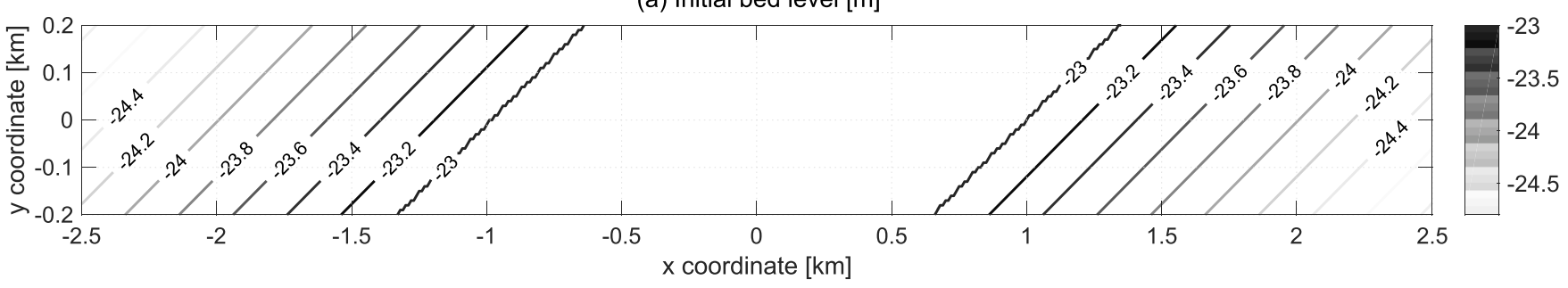

(b) Flood flow $\left[\mathrm{m} \mathrm{s}^{-1}\right]$

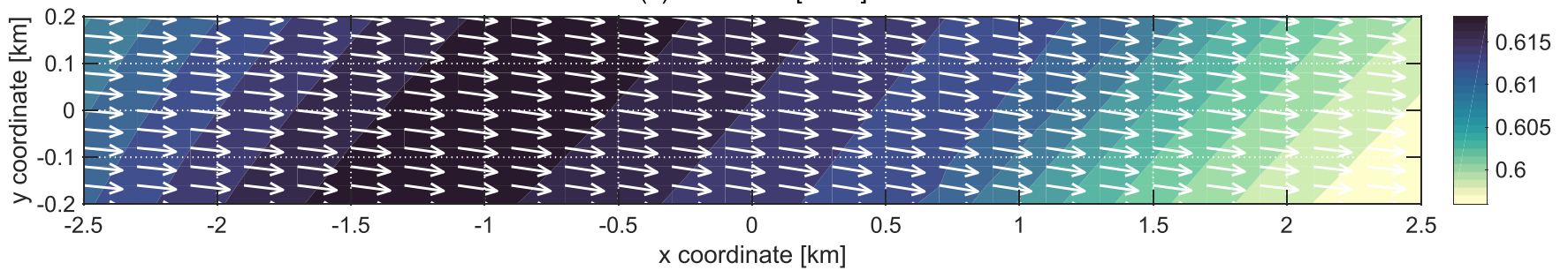

(c) Ebb flow $\left[\mathrm{m} \mathrm{s}^{-1}\right]$

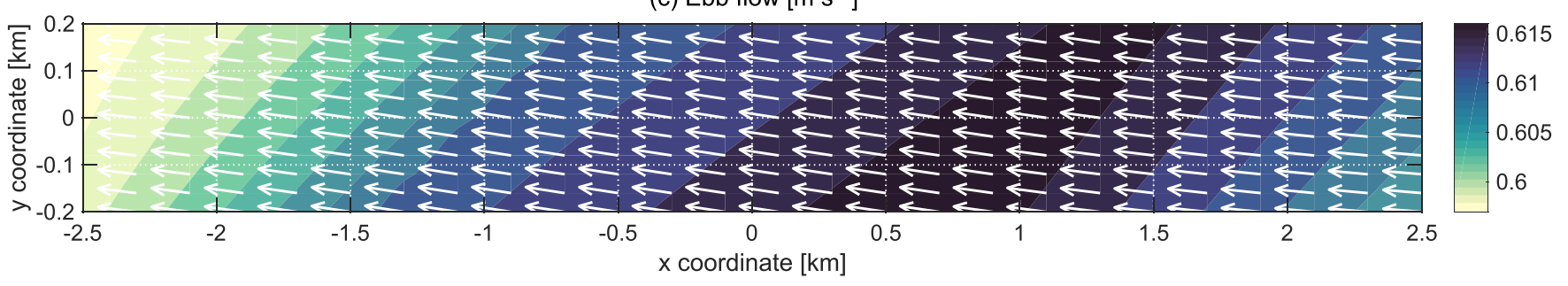

(d) Tide averaged flow $\left[\mathrm{m} \mathrm{s}^{-1}\right]$

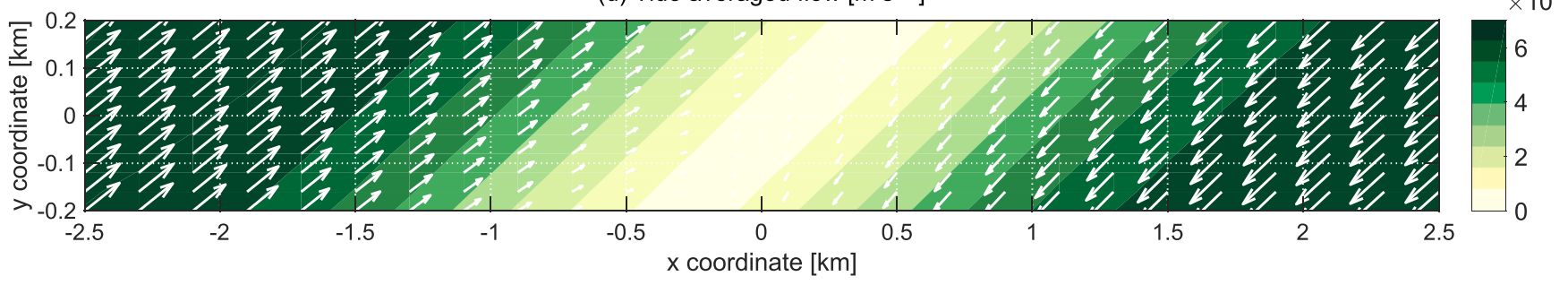

Fig. 4. Symmetrical tidal forcing $\left(S_{2}\right)$ over a sand bank with a height of $2 \mathrm{~m}$ (a), during flood flow (b), ebb flow (c) and the tide-averaged flow (d). 

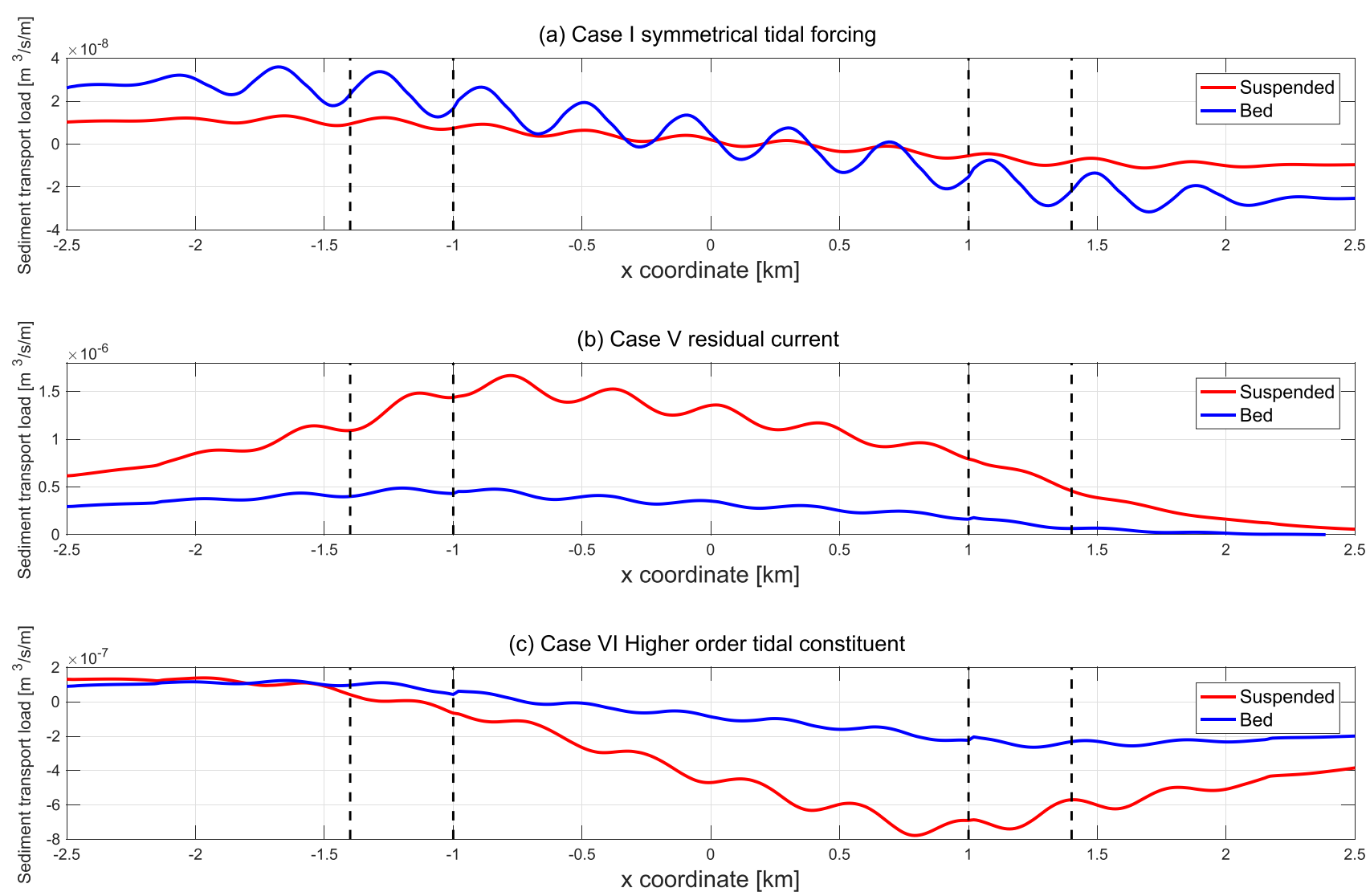

(d) Transect sand waves and sand bank

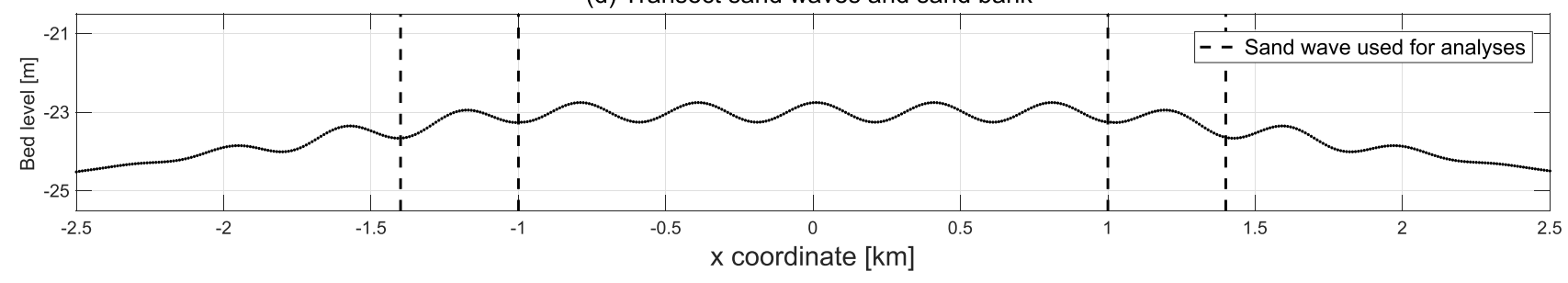

Fig. 5. Tide-averaged bed load and suspended load transport for the symmetrical tidal forcing (a), the inclusion of a residual current (b), and the inclusion of a higher order tidal constituent (c). In (d) the transect over the sand bank is displayed with the vertical black dotted lines indicating the sand waves used for analyses.

crest (for location of the sand wave crest see Fig. 5d) resulting in a growth of the sand wave crest. However, the maximum gradient in sediment transport is not exactly at the sand wave crest but located just right of the sand wave crest on the left flank of the sand bank and just left of the sand wave crest on the right flank of the sand bank (note in Fig. $5 \mathrm{a}-\mathrm{c}$, the sand wave location is presented by the black dotted vertical lines similar to Fig. 5d), resulting in a very small net migration of both sand waves towards the crest of the sand bank. In other words, the very small net horizontal tide-averaged current at both flanks of the sand bank moves the sand waves towards the crest of the sand bank.

To further investigate the migration of sand waves over a sand bank the sediment grain size and sand bank height are decreased and increased respectively. Given a fixed sand bank height, decreasing the sediment grain size from $0.35 \mathrm{~mm}$ (Case I \& III) to $0.2 \mathrm{~mm}$ (Case II \& IV), resulted in higher migration rates but still in the same order. Increasing the sand bank height, from $2 \mathrm{~m}$ (Case I \& II) to $10 \mathrm{~m}$ (Case III \& IV), resulted in an order higher migration rates for both sediment grain sizes. This shows that it is mainly the strength of the horizontal tide-averaged residual current generated by the sand bank (Figs. 11 and 12) that determines the magnitude of the migration rate.

The migration of the sand waves in Case V can be explained by the disturbance of the horizontal tide-averaged flow pattern around the sand bank. The inclusion of a residual current in flood direction on top of the symmetrical tidal forcing, result in a higher flood flow (Fig. 6b) compared to the ebb flow (Fig. 6c). Due to this difference, the resulting horizontal tide-averaged flow is in the direction of the residual current over the sand bank (Fig. 6d). The migration rate on the left flank is significantly higher compared to the symmetrical case with the same 
(a) Initial bed level [m]

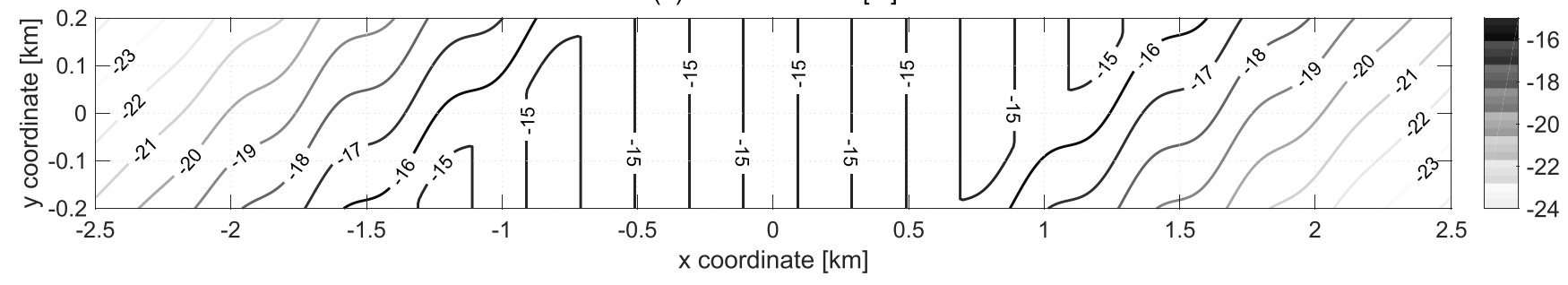

(b) Flood flow $\left[\mathrm{m} \mathrm{s}^{-1}\right]$

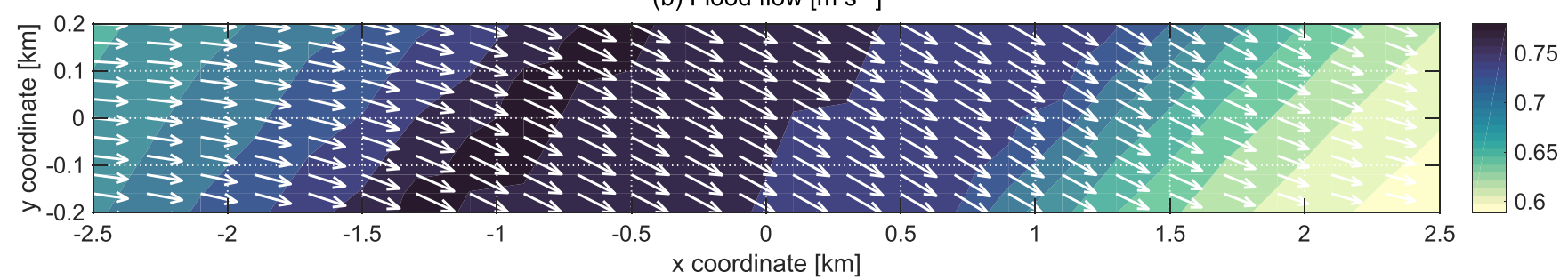

(c) Ebb flow $\left[\mathrm{m} \mathrm{s}^{-1}\right]$

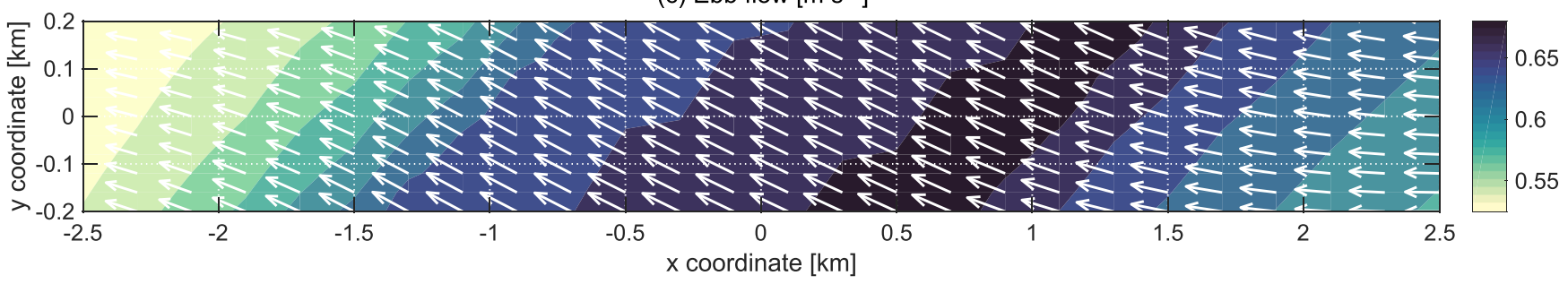

(d) Tide averaged flow $\left[\mathrm{m} \mathrm{s}^{-1}\right]$

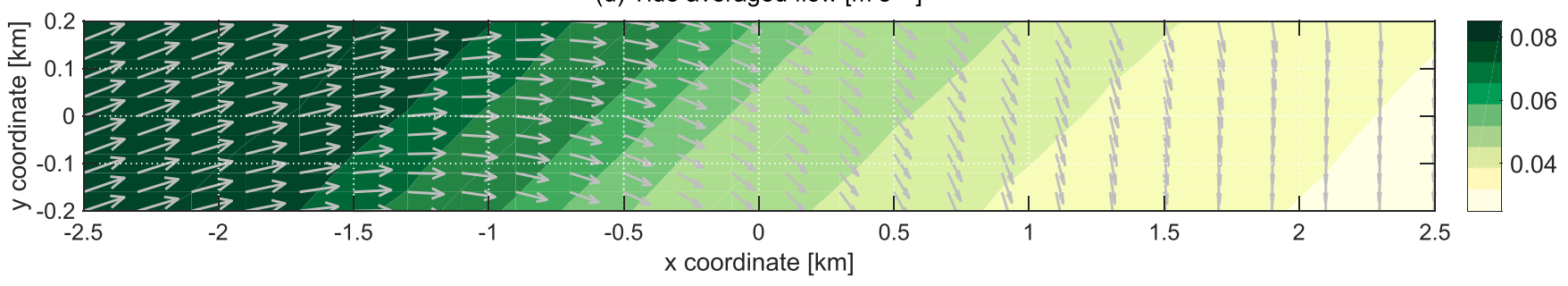

Fig. 6. Case V: symmetrical tidal forcing $\left(S_{2}\right)$ and a residual flow $\left(S_{0}\right)$ over a sand bank (a), during flood flow (b), ebb flow (c) and the tide-averaged flow (d). 
(a) Initial bed level [m]

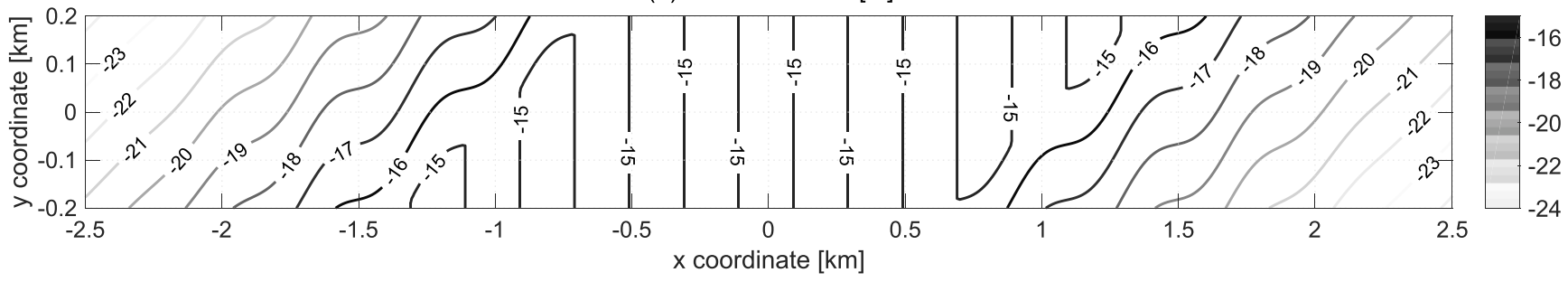

(b) Flood flow $\left[\mathrm{m} \mathrm{s}^{-1}\right]$

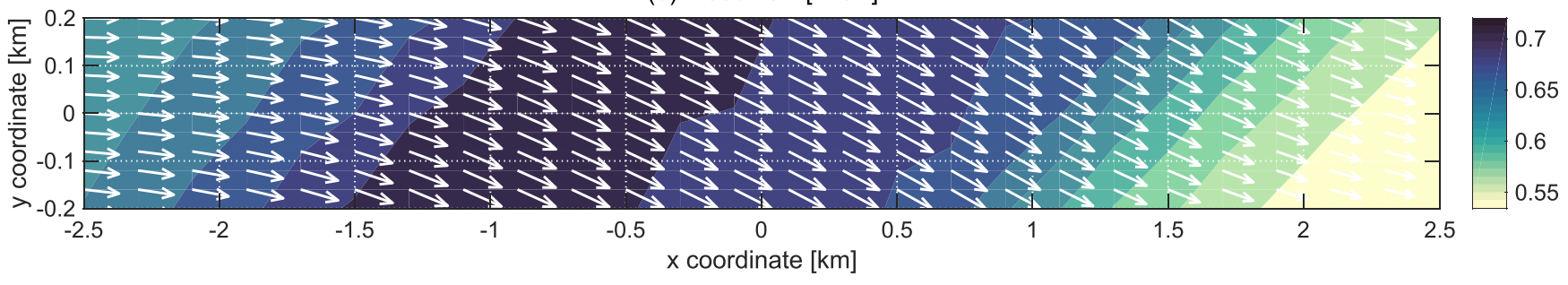

(c) Ebb flow $\left[\mathrm{m} \mathrm{s}^{-1}\right]$

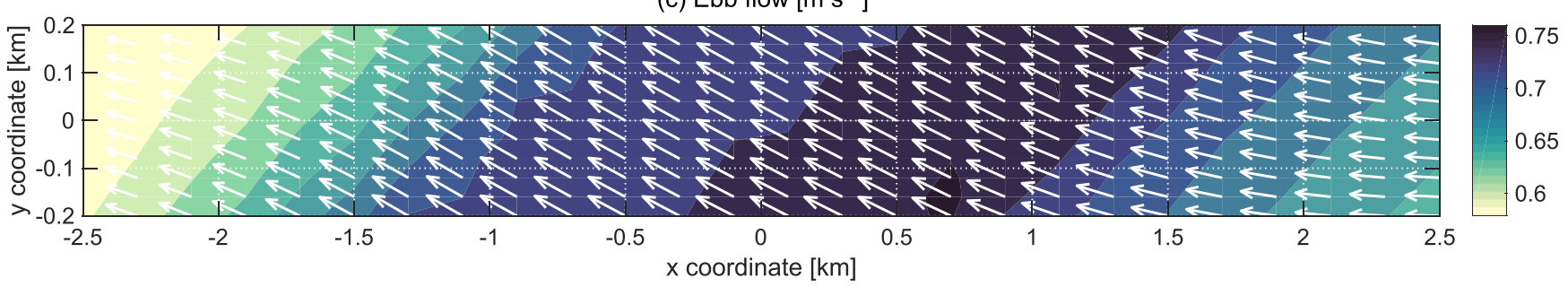

(d) Tide averaged flow [ $\left.\mathrm{m} \mathrm{s}^{-1}\right]$

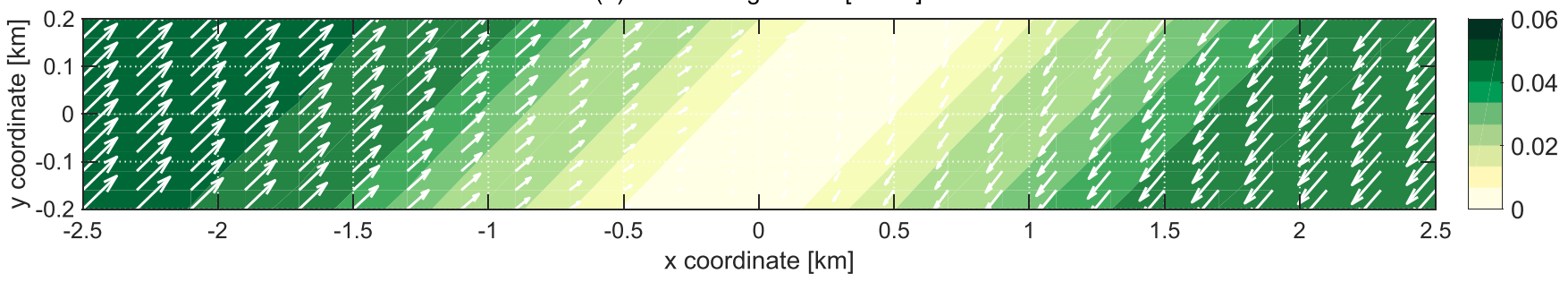

Fig. 7. Case VI: symmetrical tidal forcing $\left(\mathrm{S}_{2}\right)$ and a higher order tidal constituent $\left(\mathrm{S}_{4}\right)$ over a sand bank (a), during flood flow (b), ebb flow (c) and the tide-averaged flow (d).
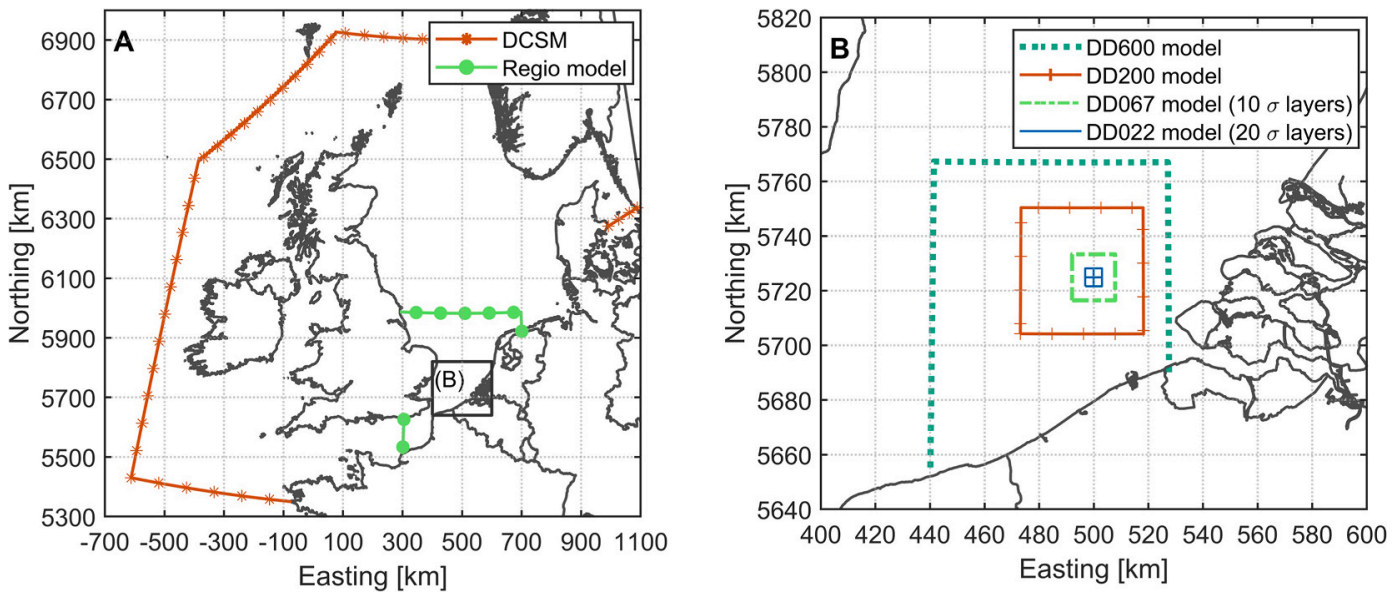

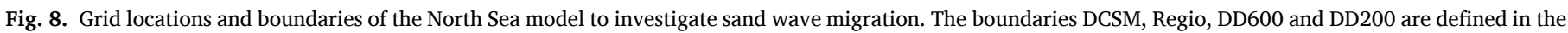
original model by Deltares (2015), the boundaries DD067 and DD022 and an extension (with vertical layers) to allow for sand wave modelling. 
sand bank height and sediment properties (Case IV), because the residual current direction coincide with the direction of the horizontal tide-averaged flow in the symmetrical case. The migration of the sand wave on the right flank is almost zero, because here the residual current is almost zero in the direction of the sand bank crest (Fig. 6d).

The horizontal tide-averaged flow pattern in Case VI (Fig. 7d) over the sand bank is qualitatively the same to the comparable cases with symmetrical tidal forcing (Case III and Case IV; Fig. 12d). However due to the asymmetrical tidal forcing the flow velocities during flood flow (Fig. 7b) are lower compared to ebb flow (Fig. 7c), resulting in tideaveraged velocities towards the sand bank crest, and hence migration of the sand waves towards the sand bank crest.

For both Case V and VI, the tide-averaged suspended sediment transport rates are larger compared to Case I (Fig. 5). For Case I we used a grain size of $0.35 \mathrm{~mm}$ and for Case V and VI we used a grain size of $0.20 \mathrm{~mm}$ (Table 1). Consequently, the suspended sediment transport rates become much larger. However, a larger suspended sediment transport rate has (for this parameter setting) a small influence on the migration speed of the sand waves (migration rates on the left flank of the sand bank are $0.53 \mathrm{~m}$ /year and $0.62 \mathrm{~m} /$ year for Case I and Case II respectively and both towards the flank of the sand bank).

\section{North Sea case-study: Borssele wind farm}

An existing model by Deltares (2015) is adopted for the North Sea case-study. Here we extend this model with two computational grids to make it possible to determine sand wave migration over a sand bank. For these additional grids the same governing equations hold as described in section 2.2. The boundary conditions and model parameters are kept the same as the original model by Deltares and are briefly described below.

\subsection{Model set-up}

\subsubsection{Original model}

In the original model by Deltares (Fig. 8a) (Deltares, 2015), four sub domains are coupled using two modelling techniques. In this way large-scale processes of the entire North Sea (Dutch continental Shelf Model (DCSM)) are modelled and linked to domains with higher resolution covering the southern part of the North Sea and Borssele Wind Farm Zone in which smaller-scale processes are important (domain Regio, DD600 and DD200). The first modelling technique (offline nesting) is used to derive boundary conditions from the DCSM for the Regio domain. The Regio, DD600 and DD200 domains are coupled using the second modelling technique (domain decomposition). In this modelling technique the domains are coupled online, meaning that they run simultaneously. The boundary conditions are defined at the outer boundaries of the Regio model and the results are transmitted automatically to the other domains in the same computation. A water level time-series is defined at the boundary of the Regio model. The boundary conditions obtained for the Regio model are extracted from the DCSM. Boundary conditions for the DCSM are driven by tidal water level variations with astronomic constituents. A set of 11 main tidal constituents was applied, including M2, S2, N2, K2, O1 and K1. Note that the amplitudes and phases of the astronomic constituents have been thoroughly calibrated; see e.g. Gerritsen et al. (1995). The Regio, DD600 and DD200 domain are run in depth-averaged mode (one vertical layer). The original model is compared with a model validated extensively on currents and water levels of the same area, and shows good agreement (Deltares, 2015).
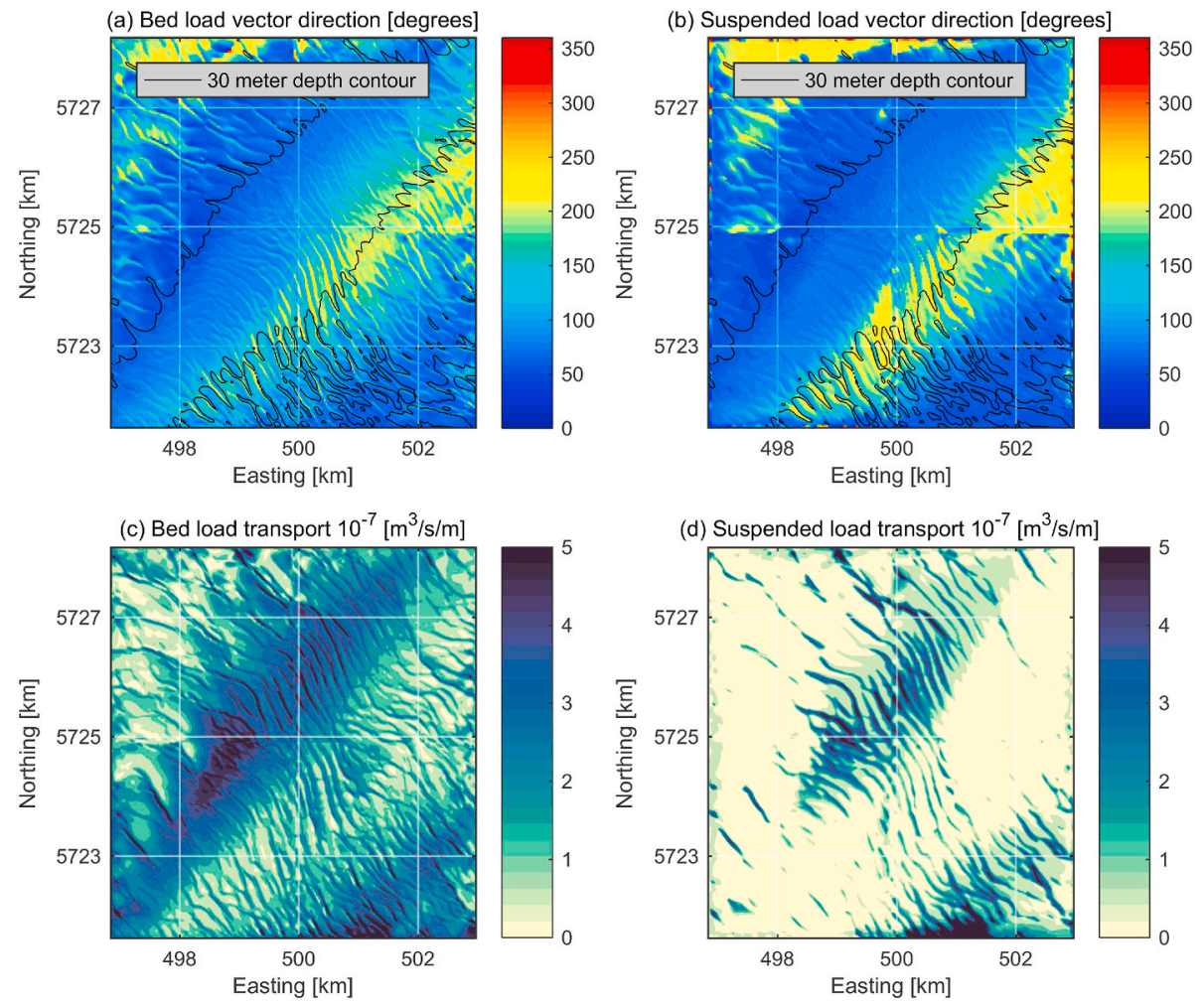

Fig. 9. In (a) and (b) the tide-averaged bed load and suspended load vector directions are displayed respectively, in degrees relative to North. In (c) and (d) the magnitude of the tide-averaged bed load and suspended load sediment transport are shown respectively. 

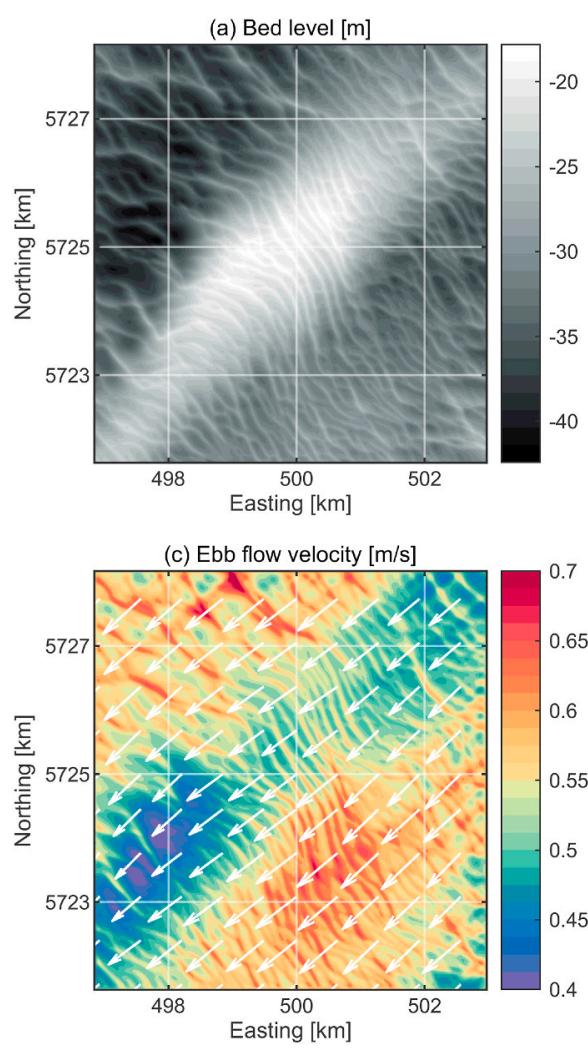
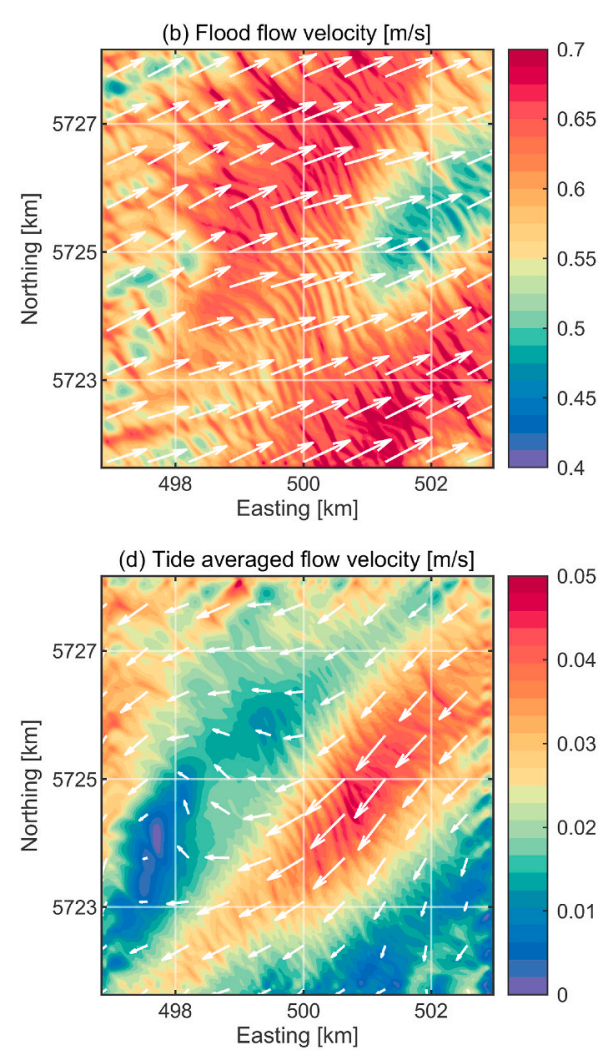

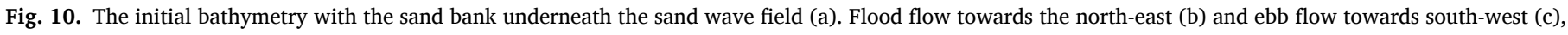
resulting in the tide-averaged flow in the ebb direction (d).

\subsubsection{Modified model}

A 3D approach (multiple vertical layers) is applied for two additional domains (named DD067 and DD022) (Fig. 8b), specifically setup for this study. The additional 3D domains with higher resolution in the horizontal are necessary to study sand wave dynamics, which is governed by three dimensional processes and requires high resolution in the horizontal as well as in the vertical plane (Borsje et al., 2013). The computational grids of the DD067 and DD022 domain have a horizontal resolution of $66.67 \mathrm{~m}$ and $22.33 \mathrm{~m}$ and a vertical resolution of 10 and 20 layers, respectively. The finest domain covers the area in which the sand bank is present under the sand wave field (Fig. 1b). Similarly to the original model of Deltares, the water level time series extracted from DSCM is applied at the boundary of the Regio model and transmitted automatically to the other domains in the same computation. The model is run for three days. The first two days are used for spin-up. During the last day output is generated to investigate the sediment transport over a tidal cycle. The seabed is not updated during the simulation. In all the domains sediment is present with a grain size diameter of $350 \mu \mathrm{m}$, which is equal to a medium grain size for the North Sea areas where sand waves are present (Borsje et al., 2009). The Chézy roughness is $65 \mathrm{~m}^{1 / 2} / \mathrm{s}$ and the turbulence formulation is according to the $k-\varepsilon$ model for the DD067 and DD022 domains (following Borsje et al. (2013, 2014)).

The model results are analysed using the tide-averaged sediment transport magnitude and direction. For sand waves over which the tideaveraged sediment transport is in one direction, with the maximum located at the sand wave crest, it is assumed that this direction is the migration direction. When the tide-averaged sediment transport load is largest at the sand wave crests and the direction is uniform over the sand wave length, the tide-averaged sediment transport load increases on the stoss side towards the crest and decreases from the crest on the lee side. The increasing transports result in erosion on the stoss side and the decreasing transports in accretion on the lee side averaged over one tidal cycle. During a spring-neap cycle the magnitudes of the tide-averaged sediment transport vary, but the direction is the same. The migration direction is therefore assumed to be the same over one tidal cycle as for multiple tidal cycles.

\subsection{Results}

For the sand wave field considered in the North Sea model, the sand bank is present diagonally under the sand wave field in the domain considered (Fig. 1b). Looking at the migration direction derived from historical bathymetric survey data (Fig. 1c), the negative values indicate migration towards the south-west, whereas positive values indicate migration towards the north-east. The observed transition in migration direction of sand waves over the sand bank is approximately north-south directed. Considering the model results, the directions of the tideaveraged sediment transport vectors are displayed for bed load and suspended load in Fig. 9a and Fig. 9b respectively. For both figures, the vector directions are in degrees relative to North. The $30 \mathrm{~m}$ depth contour distinguish the top of the sand bank and the deeper parts, showing the west and east side of the sand bank. An area is distinguished with vectors pointing approximately towards the north-east, so vector direction magnitudes of around $60^{\circ}$ (dark blue colours around west side sand bank). Secondly, an area with vectors pointing approximately towards the south-west is distinguished, so vector direction magnitudes of around $220^{\circ}$ (yellow colours around east side sand bank). In addition to the direction, the magnitudes of the tide-averaged sediment transport 
load are displayed in Fig. 9c and d for bed load and suspended load respectively. For both bed load and suspended sediment load transport, the magnitudes are larger at the sand waves crest compared to the trough. With the combination of a maximum tide-averaged sediment load at the sand waves crest and the uniform direction over the sand wave length, the assumed migration can be derived as explained in Subsection 4.1.2. Bidirectional migration of sand waves is present over the sand bank. On the west side of the sand bank the sand waves migrate approximately towards the north-east (dark blue colours) and on the east side towards the south-west (yellow colours).

\subsubsection{Physical explanation}

In the North Sea model, the resulting migration can be explained by the complex bathymetry Fig. 10a) together with the asymmetrical tidal signal. The asymmetrical tidal signal is characterized by higher flow velocities during flood flow (Fig. 10b) compared with the flow velocities during ebb flow (Fig. 10c). Furthermore the flood period is shorter compared to the ebb period. During flood flow the flow accelerates towards the top of the sand bank, and decelerates downstream of the top resulting in an area with low velocities behind the sand bank in the direction of the flow. The largest flow velocities are present in the deeper areas alongside the sand bank, because the flow is deflected around the sand bank. The flow experiences a clockwise deflection, enhanced by the Coriolis effect (Northern Hemisphere). During ebb flow the same mechanism is observed, but with lower velocities (Fig. 10c). The flood and ebb flow result in the tide-averaged flow velocities and directions displayed in Fig. 10d. The tide-averaged flow is in the ebb direction because the ebb period is longer compared to the flood period. Low tideaveraged flow velocities are observed in areas where the asymmetry in the flood flow direction is relatively large, meaning that the flood flow is dominantly present (blue areas Fig. 10d). Areas in which the ebb flow is dominantly present have relatively large magnitudes during ebb flow, resulting in tide-averaged flow velocities of around $5 \mathrm{~cm} / \mathrm{s}$ (red areas Fig. 10d). The area in which the flood flow is dominantly present can be related to the area in Fig. 9a and b where the tide-averaged sediment vectors are directed to the north-east along the west side of the sand bank. The area in which the ebb flow is dominantly present can be related to the vector direction in Fig. 9a and b pointing towards the south-west along the east side of the sand bank. The presence of the tidal sand bank thus influences the tide-averaged hydrodynamics and sediment dynamics and thereby creates areas where the tide-averaged sediment transport in the ebb direction is enhanced and areas where the tide-averaged sediment transport in the flood direction is enhanced. This results in a sand wave migration towards the north east on the west side of the sand bank and to the south west on the east side of the sand bank. Consequently, the model results show reasonable agreement with field observations (Fig. 1).

\section{Discussion}

In this paper, we studied the migration of sand waves over a sand bank. We focussed on the processes responsible for the bidirectional migration of sand waves over a sand bank in the Schematized model, and the applicability of the North Sea model to model sand wave migration patterns in the field.

The migration direction of small amplitude sand waves is examined in the Schematized model for the initial stage. When sand waves grow towards an equilibrium sand wave height, the migration direction decreases, but simulations with larger sand waves (up to $5 \mathrm{~m}$ ) still show bidirectional migration of sand waves over a sand bank with a rate up to tens of centimetres per year (not shown here).

Furthermore, the water depth and sediment grain size vary between Cases in the Schematized model. These variations would result in different lengths for the fastest growing mode, over the sand bank and for different grain sizes. Borsje et al. (2013) showed that the migration rate of sand waves with different lengths differs only slightly. The migration rate might therefore differ slightly over the sand bank when another length for the fastest growing mode is chosen, but the overall conclusions regarding the migration mechanism still holds. In the Schematized model, the migration direction is determined for a sand wave on either side of the sand bank along the transect perpendicular to the sand waves (Fig. 3e). Symmetrical tidal forcing is used to examine the influence on sand wave migration of a sand bank solely. In the middle of the domain $(x=0 \mathrm{~km})$ the tide-averaged sediment transports are not exactly zero, for bed load and suspended load transport (Fig. 5a). This indicates an asymmetry in the flood flow compared to the ebb flow and the resulting sediment transports and migration rates on both flanks for the symmetrical cases. Most likely, this asymmetry is the result of the schematization of the infinite long sand bank in a finite domain.

Modelling sand wave processes in the North Sea model required vertical resolution in the original model by (Deltares, 2015). A vertical resolution following (Borsje et al., 2013, 2014) is used in the model modification. To obtain computational efforts in the order of days, the finest domain is subdivided into four domains with the same resolution. The coupling of these sub domains using the domain decomposition techniques introduced numerical errors at the boundaries. These errors are part of using this model technique. The area of interest is however not located at these boundaries and the bidirectional migration of sand waves found in this paper is comparable to the field data. In future sand wave modelling, different modelling techniques like Delft3D Flexible Mesh might be considered. With this modelling technique one domain is sufficient to increase the vertical and horizontal resolution locally and thereby exclude domain boundaries within the model.

Part of using complex numerical models, are the large computational efforts needed. The results in this paper are based on output of one tidal cycle for which the computational time including spin-up of the model was $22 \mathrm{~h}$ and $25 \mathrm{~h}$ for the Schematized model and North Sea model respectively. Regarding the Schematized model, we can conclude that one tidal cycle was sufficient to run. We checked the migration rates after 13 and 60 tidal cycles (not shown here) and the difference in migration rates was within $6 \%$ of the migration rates after 1 tidal cycle. To model longer-term migration patterns (engineering purposes) using the North Sea model, powerful computational resources are required.

\section{Conclusions}

The migration direction of sand waves over a sand bank is studied using the numerical shallow water model Delft3D by incorporating both bed load and suspended load sediment transport. The Schematized model revealed that sand waves migrate with some meters per year towards the top of the sand bank due to the alteration of the tidal flow by the presence of the sand bank. The component of the horizontal tideaveraged flow towards the top of the sand bank disturbs the vertical tide-averaged recirculating cells of sand waves thereby causing bidirectional migration of sand waves over the sand bank.

Next, in the case-study the North Sea model revealed that sand wave migration directions observed in the field are reasonably reproduced by the model, thereby opening opportunities for consultancy practices. 


\section{Declaration of competing interest}

The authors declare that they have no known competing financial interests or personal relationships that could have appeared to influence the work reported in this paper.

\section{Acknowledgements}

The authors would like to acknowledge Deltares, Netherlands for funding this research as part of the strategic research program Coastal and Offshore engineering. In addition, the authors acknowledge NWO, Royal Boskalis Westminster N.V. and Royal Netherlands Institute for Sea Research (NIOZ) for financing the SANDBOX programme.

\section{Appendix}

(a) Initial bed level [m]

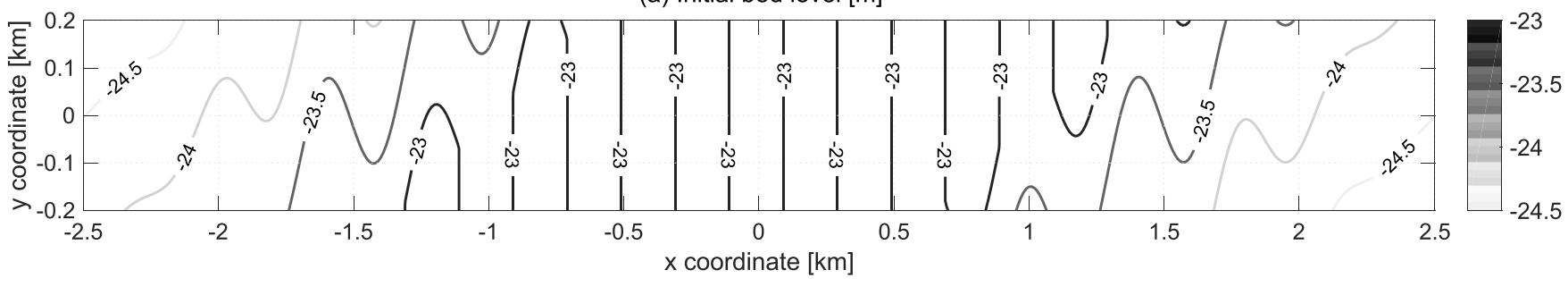

(b) Flood flow $\left[\mathrm{m} \mathrm{s}^{-1}\right]$

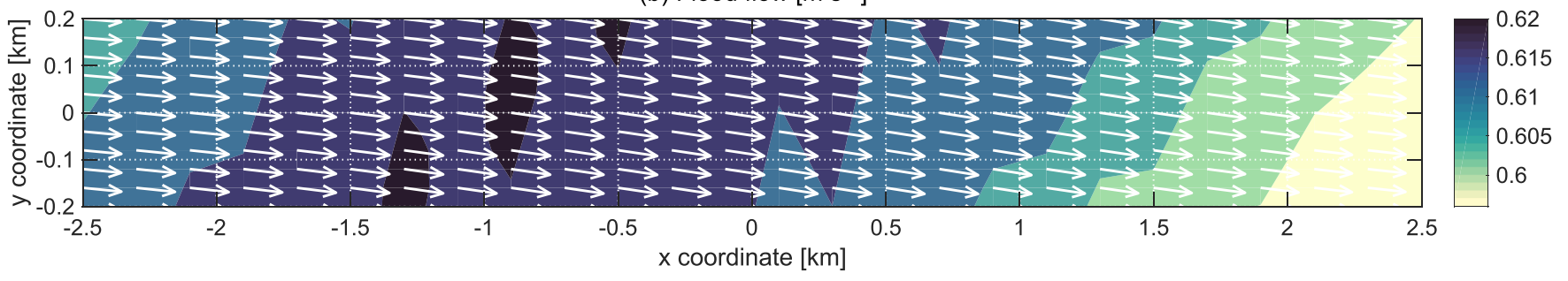

(c) Ebb flow $\left[\mathrm{m} \mathrm{s}^{-1}\right]$

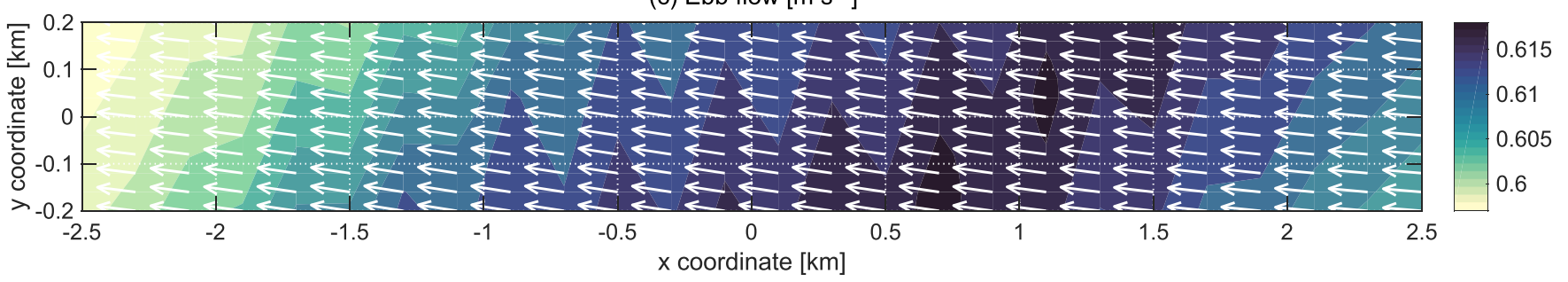

(d) Tide averaged flow $\left[\mathrm{m} \mathrm{s}^{-1}\right]$

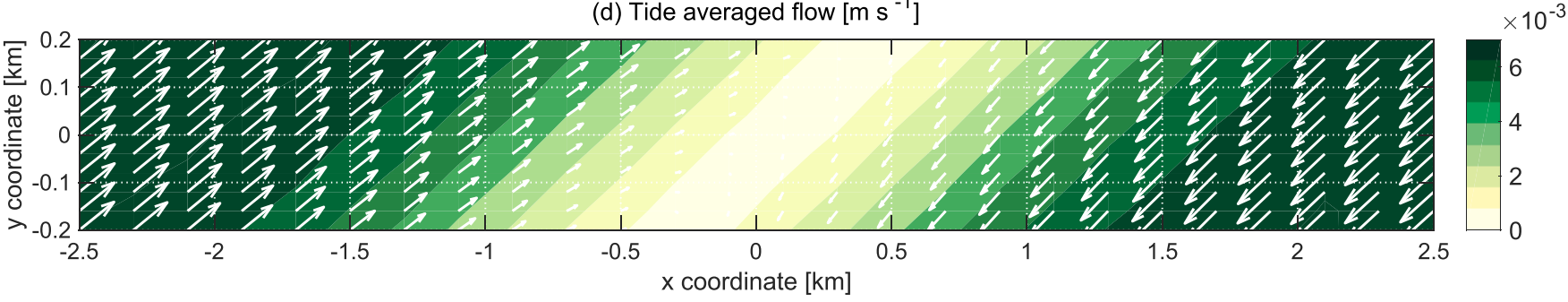

Fig. 11. Case I and Case II: symmetrical tidal forcing $\left(S_{2}\right)$ over a sand bank (a), during flood flow (b), ebb flow (c) and the tide-averaged flow (d). 
(a) Initial bed level [m]

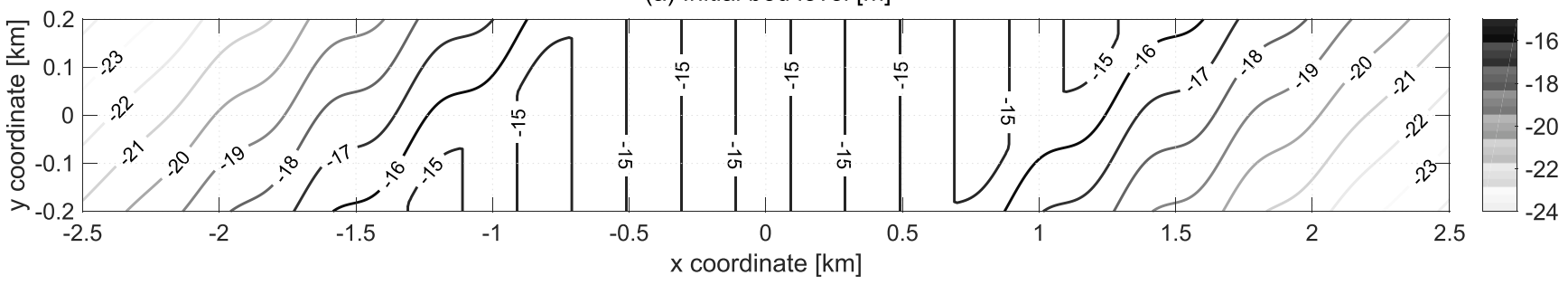

(b) Flood flow $\left[\mathrm{m} \mathrm{s}^{-1}\right]$

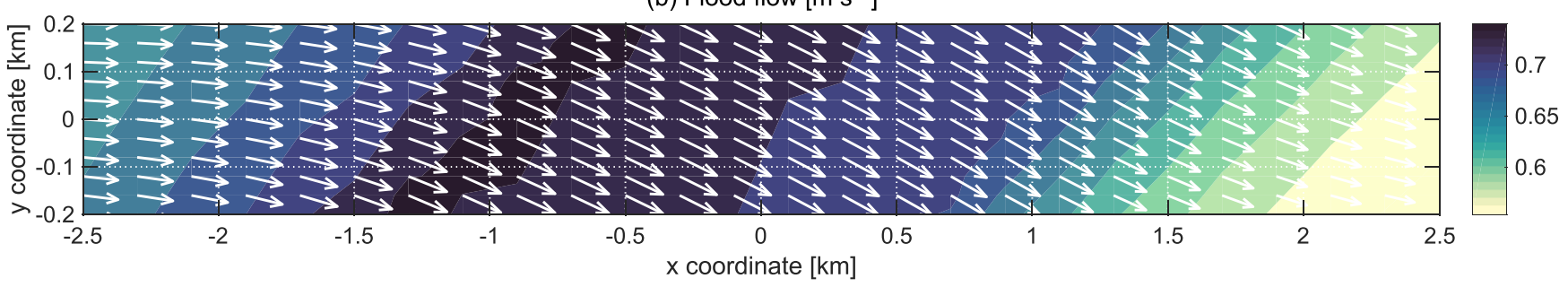

(c) Ebb flow $\left[\mathrm{m} \mathrm{s}^{-1}\right]$

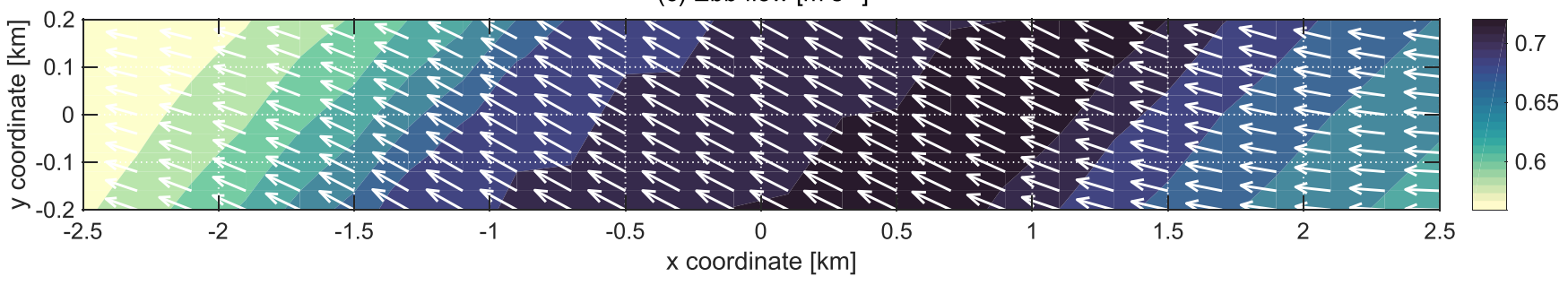

(d) Tide averaged flow $\left[\mathrm{m} \mathrm{s}^{-1}\right]$

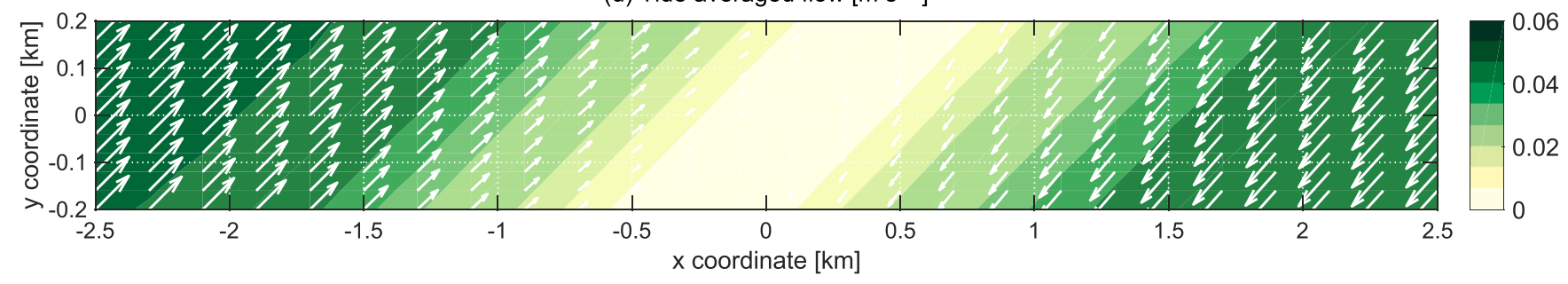

Fig. 12. Case III and Case IV: symmetrical tidal forcing ( $\left.S_{2}\right)$ over a sand bank (a), during flood flow (b), ebb flow (c) and the tide-averaged flow (d).

\section{Author statement}

Sjoerd Leenders: Conceptualization, Methodology, Writing - Original Draft, Visualization, Software.

Johan Damveld: Writing - Original Draft, Formal analysis.

Jan-Joost Schouten: Writing - Review \& Editing, Funding acquisition, Supervision.

Roderik Hoestra: Writing - Review \& Editing, Software.

Tom J. Roetert: Writing - Review \& Editing, Software.

Bas W. Borsje: Conceptualization, Methodology, Writing - Review \& Editing.

\section{References}

Besio, G., Blondeaux, P., Brocchini, M., Hulscher, S.J.M.H., Idier, D., Knaapen, M.A.F., Németh, A.A., Roos, P.C., Vittori, G., 2008. The morphodynamics of tidal sand waves: a model overview. Coast. Eng. 55, 657-670.

Besio, G., Blondeaux, P., Brocchini, M., Vittori, G., 2004. On the modeling of sand wave migration. J. Geophys. Res. Ocean. 109.

Besio, G., Blondeaux, P., Frisina, P., 2003a. A note on tidally generated sand waves. J. Fluid Mech. 485, 171-190.

Besio, G., Blondeaux, P., Brocchini, M., Vittori, G., 2003b. Migrating sand waves. Ocean Dynam. 53, 232-238.

Besio, G., Blondeaux, P., Vittori, G., 2006. On the formation of sand waves and sand banks. J. Fluid Mech. 557, 1-27. https://doi.org/10.1017/S0022112006009256.
Blondeaux, P., Vittori, G., 2016. A model to predict the migration of sand waves in shallow tidal seas. Continent. Shelf Res. 112, 31-45.

Blondeaux, P., Vittori, G., 2005a. Flow and sediment transport induced by tide propagation: 1. The flat bottom case. J. Geophys. Res. Ocean. 110.

Blondeaux, P., Vittori, G., 2005b. Flow and sediment transport induced by tide propagation: 2. The wavy bottom case. J. Geophys. Res. Ocean. 110.

Blondeaux, P., Vittori, G., Mazzuoli, M., 2016. Pattern formation in a thin layer of sediment. Mar. Geol. 376, 39-50.

Borsje, B.W., de Vries, M.B., Bouma, T.J., Besio, G., Hulscher, S.J.M.H., Herman, P.M.J. 2009. Modeling bio-geomorphological influences for offshore sandwaves. Continent. Shelf Res. 29, 1289-1301.

Borsje, B.W., Kranenburg, W.M., Roos, P.C., Matthieu, J., Hulscher, S.J.M.H., 2014. The role of suspended load transport in the occurrence of tidal sand waves. J. Geophys. Res. Earth Surf. 119, 701-716. 
Borsje, B.W., Roos, P.C., Kranenburg, W.M., Hulscher, S.J.M.H., 2013. Modeling tidal sand wave formation in a numerical shallow water model: the role of turbulence formulation. Continent. Shelf Res. 60, 17-27. https://doi.org/10.1016/j. csr.2013.04.023.

Burchard, H., Craig, P.D., Gemmrich, J.R., van Haren, H., Mathieu, P.-P., Meier, H.E.M., Wijesekera, H.W., 2008. Observational and numerical modeling methods for quantifying coastal ocean turbulence and mixing. Prog. Oceanogr. 76 (4), 399-442. https://doi.org/10.1016/j.pocean.2007.09.005.

Campmans, G.H.P., Roos, P.C., de Vriend, H.J., Hulscher, S.J.M.H., 2017. Modeling the influence of storms on sand wave formation: a linear stability approach. Continent. Shelf Res. 137, 103-116.

Damveld, J.H., Roos, P.C., Borsje, B.W., Hulscher, S.J.M.H., 2019. Modelling the twoway coupling of tidal sand waves and benthic organisms A linear stability approach. Environ. Fluid Mech. 19 (5), 1073-1103. https://doi.org/10.1007/s10652-01909673-1.

Deltares, 2016a. Morphodynamics of Borssele Wind Farm Zone WFS-III, WFS-IV and WFS-V Update Version January 25th, 2016.

Deltares, 2016b. Morphodynamics of $\{\mathrm{H}\}$ ollandse $\{\mathrm{K}\}$ ust (Zuid) Wind Farm Zone.

Deltares, 2015. Site Studies Wind Farm Zone Borssele, Metocean Study for Borssele Wind Farm Zone Site 1.

Deltares, 2012. User Manual Delft-3D FLOW. Report. Deltares, Delft, The Netherlands.

Dodd, N., Blondeaux, P., Calvete, D., De Swart, H.E., Falqués, A., Hulscher, S.J.M.H. Różyński, G., Vittori, G., 2003. Understanding coastal morphodynamics using stability methods. J. Coast Res. 849-865.

EU-OEA, 2012. Seanergy 2020 - delivering offshore electricity to the EU: spatial planning of offshore renewable energies and electricity grid infrastructures in an integrated EU maritime policy. Eur. Wind Energy Assoc. 80.

Gerkema, T., 2000. A linear stability analysis of tidally generated sand waves. J. Fluid Mech. 417, 303-322.

Gerritsen, H., De Vries, H., Philippart, M.J.C., studies, e., 1995. The Dutch Continental Shelf Model, 425-425.

Hulscher, S.J.M.H., 1996. Tidal-induced large-scale regular bed form patterns in a threedimensional shallow water model. J. Geophys. Res. Ocean. 101, 20727-20744.

Jiang, W., Lin, M., 2016. Research on bilateral reverse migration of one-group seabed sand waves in small shallow shelf sea. CoastalEngineering111:70-82. https://doi. org/10.1016/j.coastaleng.2016.01.013.

Jeffrey, H., Sedgwick, J., 2011. ORECCA European Offshore Renewable Energy Roadmap. ORECCA European Offshore Renewable Energy Roadmap.
Knaapen, M.A.F., Hulscher, S.J.M.H., Vriend, H.J., Stolk, A., 2001. A new type of sea bed waves. Geophys. Res. Lett. 28, 1323-1326.

Komarova, N.L., Hulscher, S.J.M.H., 2000. Linear instability mechanisms for sand wave formation. J. Fluid Mech. 413, 219-246.

Lesser, G.R., Roelvink, J.A., Van Kester, J., Stelling, G.S., 2004. Development and validation of a three-dimensional morphological model. Coast. Eng. 51, 883-915.

Nemeth, A., Hulscher, S.J.M.H., de Vriend, H.J., 2003. Offshore sand wave dynamics, engineering problems and future solutions. Pipeline Gas J. 230, 67-69.

Németh, A.A., Hulscher, S.J.M.H., de Vriend, H.J., 2002. Modelling sand wave migration in shallow shelf seas. Continent. Shelf Res. 22, 2795-2806.

Németh, A.A., Hulscher, S.J.M.H., Van Damme, R.M.J., 2007. Modelling offshore sand wave evolution. Continent. Shelf Res. 27, 713-728. https://doi.org/10.1016/j. csr.2006.11.010.

Németh, A.A., Hulscher, S.J.M.H., Van Damme, R.M.J., 2006. Simulating offshore sand waves. Coast. Eng. 53, 265-275.

Roetert, T., Raaijmakers, T., Borsje, B., 2017. Cable route optimization for offshore wind farms in morphodynamic areas. Proc. Int. Offshore Polar Eng. Conf. ISOPE-I-17-469 https://www.onepetro.org/conference-paper/ISOPE-I-17-469.

Roos, P.C., Hulscher, S.J.M.H., 2003. Large-scale seabed dynamics in offshore morphology: modeling human intervention. Rev. Geophys. 41 https://doi.org/ 10.1029/2002RG000120.

Van den Berg, J., Sterlini, F., Hulscher, S.J.M.H., van Damme, R., 2012. Non-linear process based modelling of offshore sand waves. Continent. Shelf Res. 37, 26-35. https://doi.org/10.1016/j.csr.2012.01.012.

Van Gerwen, W., Borsje, B.W., Damveld, J.H., Hulscher, S.J.M.H., 2018. Modelling the effect of suspended load transport and tidal asymmetry on the equilibrium tidal sand wave height. Coast. Eng. 136, 56-64. https://doi.org/10.1016/j. coastaleng.2018.01.006.

Van Oyen, T., Blondeaux, P., 2009a. Grain sorting effects on the formation of tidal sand waves. J. Fluid Mech. 629, 311-342.

Van Oyen, T., Blondeaux, P., 2009b. Tidal sand wave formation: influence of graded suspended sediment transport. J. Geophys. Res. Ocean. 114.

Van Rijn, L.C., 2007. Unified view of sediment transport by currents and waves. I: initiation of motion, bed roughness, and bed-load transport. J. Hydraul. Eng. 133 (6), 649-667. https://doi.org/10.1061/(ASCE)0733-9429, 2007)133:6(649).

Verboom, G.K., Slob, A., 1984. Weakly-reflective boundary conditions for twodimensional shallow water flow problems. Adv. Water Resour. 7, 192-197. https:// doi.org/10.1016/0309-1708(84)90018-6. 